\title{
VIDA Y EMPRESAS DEL CARDENAL LLUÍS JOAN DEL MILÀ: PROMOCIÓN ECLESIÁSTICA Y MECENAZGO ENTRE ITALIA Y LA CORONA DE ARAGÓN
}

\author{
LIFE AND ENDEAVOURS OF CARDINAL LLUÍS JOAN DEL MILÀ: ECCLESIASTICAL \\ PROMOTION AND PATRONAGE BETWEEN ITALY AND THE CROWN OF ARAGON
}

\section{Álvaro Fernández de Córdova Miralles \\ Universidad de Navarra}

Resumen: El presente trabajo ofrece una aproximación biográfica a Lluís Joan del Milà, sobrino del papa Calixto III y futuro "cardenal de Albaida". Partiendo de su promoción eclesiástica al amparo de su tío, se analiza su actividad al servicio de Pío II y Paulo II, su proyecto señorial en tierras valencianas, sus contactos intelectuales y las empresas artísticas impulsadas en Roma, Viterbo y el valle de Albaida. En el ámbito político-eclesiástico se contemplan sus ambiguas relaciones con la Corona y su gobierno en las diócesis de Segorbe y Lérida, donde las preocupaciones familiares asfixiaron sus responsabilidades pastorales. Son las luces y las sombras de este prelado del Renacimiento que vivió entre dos penínsulas en intensa transformación artística y religiosa.

Palabras clave: Lluís Joan del Milà, Colegio cardenalicio, Promoción eclesiástica, Roma, Corona de Aragón, Valencia, Lérida, Mecenazgo artístico, Humanismo.
Abstract: This paper provides a biographical approach to Joan Lluís del Mila, nephew of Pope Callistus III and future "Cardinal of Albaida". Beginning from his ecclesiastical promotion under the patronage of his uncle, it analyzes his activity in the service of Pius II and Paul II. It goes further to investigate his project to establish a feudal lordship in the region of Valencia, his contacts in the intellectual circles, and the artistic projects that he promoted in Rome, Viterbo and the Albaida Valley. In the politico-ecclesiastical sphere, his ambiguous relationship with the Crown and his government in the dioceses of Lérida and Segorbe, where the family concerns suffocated his pastoral responsibilities, are examined. These are the lights and shadows of the Renaissance prelate who lived between two peninsulas that were undergoing intense artistic and religious transformation.

Keywords: Lluís Joan del Milà, College of Cardinals, Ecclesiastical Promotion, Rome, Crown of Aragon, Valence, Lerida, Patronage, Renaissance Humanism. 
La figura de Lluís Joan del Milà, conocido como "cardenal de Albaida", no ha sido objeto de ningún estudio monográfico que vaya más allá de escuetas semblanzas más o menos documentadas ${ }^{1}$. El personaje comenzó a surgir desde las brumas de la imprecisión histórica gracias a las notas de Lorenzo Cardella y Alfonso Chacón, completadas más tarde por la erudita información de Villanueva. En el siglo XX, Llorens Raga, Pascual i Beltrán, y especialmente Rius Serra y Batllori aportaron precisiones documentales sobre la familia y la carrera eclesiástica de algunos de sus miembros. Gracias a ello se ha podido trazar más recientemente el itinerario vital del personaje en las líneas que le han dedicado Goñi Gaztambide, Pons Alòs, Hinojosa Montalvo y París. Con todo, las investigaciones no han dejado de ampliar nuestro conocimiento, especialmente sobre su promoción a la sombra de su tío Calixto III (Navarro Sorní), su patrimonio señorial en el valle de Albaida (Terol i Reig) o el castillo-palacio que allí hizo levantar (Soler i Molina). Falta sin embargo un estudio global que incorpore a estos materiales las huellas que el cardenal dejó en Roma, sus contactos intelectuales y empresas artísticas que explican sus proyectos en Valencia y Lérida, o sus singulares relaciones con el poder real durante el reinado de Juan II y Fernando el Católico. Sólo una fecunda integración de estos elementos permitirá comprender la personalidad y el legado de este cardenal del Renacimiento que vivió entre dos penínsulas - la ibérica y la italiana - en uno de los períodos de mayor intensidad artística y cultural.

\section{A la sombra de Alfonso de Borja}

Como los Borja, los Milà eran una familia de ciudadanos de Játiva, documentada al menos desde principios del siglo XIV, que prosperó gracias a los cargos ocupados en la ciudad, a los oficios cortesanos otorgados por Alfonso

1.- Para no multiplicar las citas remitimos a las entradas, más o menos recientes, de José GoÑI GAZtambide, "Mila, Luis Juan de", en Quintín Aldea Vaquero, Tomás Marín Martínez, José Vives Gatell, Diccionario de Historia Eclesiástica de España, vol. Suplemento, Madrid, Instituto Enrique Flórez, 1987, pp. 489-492; Álvaro Fernández de Córdova Miralles, Alejandro VI y los Reyes Católicos. Relaciones político-eclesiásticas (1492-1503), Roma, Edizioni Università della Santa Croce, 2005, pp. 109-110 y 223-225; V. Pons Alòs, Cardenales y prelados de Xàtiva en la época de los Borja, Játiva, Iglesia Colegial Basílica de Santa María-Centro de Estudios Borgianos, 2005, pp. 57-62; Josefina PARís, "Episcopologi (segles XIII-XV)", en Arrels cristianes: presència i significació del cristianisme en la història i la societat de Lleida, vol. III: Temps de consolidacio. La Baixa Edat Mitjana, Lérida, Pagès-Bisbat de Lleida, 2009, pp. 657-658; José Hinojosa Montalvo, "Milà i Borja, Lluís Joan de", en Diccionario Biográfico Español, vol. 35, Real Academia de la Historia, Madrid, 2012, p. 115. El sitio web de Salvador Miranda: http://www2.fiu.edu/ mirandas/bios1456.htm\#Mila. No hemos podido consultar al trabajo de A. SoLER, "El cardenal d'Albaida Lluís Joan del Milà i Borja i la seua família" (conferencia mecanografiada 8.V.2003). 
el Magnánimo y a las prebendas eclesiásticas recibidas por la influencia del cardenal Alfonso de Borja. Lluís Joan era el segundo hijo de Joan del Milà y Centelles $(† 1460)$ — caballero y señor de Massalavés - y de Caterina de Borja, hermana de Alfonso de Borja, obispo de Valencia, cardenal y futuro Calixto III. Fruto de este matrimonio, cuyas capitulaciones datadas en $1447^{2}$ deben proceder de un momento anterior ${ }^{3}$, nacieron tres hijos: Pere, Damiata y Lluís Joan. El ascenso eclesiástico de Alfonso de Borja debió provocar el traslado a Roma de la familia Milà-Borja con todos sus efectivos procedentes de Nápoles o de Valencia. Al grupo del rey pertenecía Pere - el hermano mayor de Lluís Joan-que sirvió a Alfonso V como camarero y en las guerras de Nápoles donde fue gobernador de Tropea y de otras tierras de Calabria hasta su fallecimiento en $1455^{4}$.

Lluís Joan había nacido en Játiva hacia 1432/1433 y como segundón fue destinado a la carrera eclesiástica que inició a los nueve años a expensas de su tío. Éste presionó al rey Alfonso para que lograra en su favor el primer beneficio vacante de la colegiata de Játiva (26.XII.1441) y solicitase a Eugenio IV una dispensa que le permitiera acceder a una canonjía en la catedral de Valencia a pesar de su corta edad (12.VII.1443), además de una reserva de una canonjía y una cabiscolía en la colegiata setabense ${ }^{5}$. Del cardenal Borja obtuvo además una reserva de cuatro canonjías en la catedral de Valencia una de las cuales adjudicada para Lluís Joan cuando quedara libre - pero al no producirse la vacante obtuvo antes el nombramiento de canónigo y chantre de la colegiata de Játiva (8.VIII.1447). Poco después el cardenal tuvo que intervenir cuando algunos competidores obstaculizaron la canonjía valenciana

2.- Miquel Batllori, Obra completa, ed. E. Duran y J. Solervicens, vol. IV: La família Borja, Valencia, Tres i Quatre, 1994, ad indicem; ID., "La estirpe de los Borjas: del siglo XII al XVI", en ID., La familia de los Borjas, Madrid, Real Academia de la Historia, 1999, p. 23.

3.- Paulino Iradiel y José María Cruselles, "El entorno eclesiástico de Alejandro VI. Notas sobre la formación de la clientela política borgiana (1429-1503)", en Maria Chiabò, Silvia Maddalo y Massimo Miglio (coords.), Roma di fronte all'Europa al tempo di Alessandro VI. Atti del Convegno (Città del Vaticano-Roma, 1-4 dicèmbre 1999), vol. I, Roma, Ministero per i Beni e le Attivita Culturali, 2001, p. 34.

4.- Sobre este personaje ver José Rius SERra, "Catalanes y aragoneses en la corte de Calixto III”, Analecta Sacra Tarraconensia, 3 (1927), p. 272 (con una confusa identificación de padre e hijo); BATLLORI, Obra completa, vol. IV, p. 10. Algunos documentos que muestran ciertos préstamos monetarios al rey Alfonso de Nápoles (22.II.1447) y su actividad de enlace entre éste y el cardenal Alfonso de Borja (4.IV.1445), figuran en Carlos LóPez Rodríguez (dir.), Diplomatari Borja. 4: Documents de l'Arxiu de la Corona d'Aragó (1444-1458), Valencia, Edicions 3i4, 2008, pp. $62-65$ (doc. 23) y 112 (doc. 64).

5.- Carlos López Rodríguez (dir.), Diplomatari Borja. 3: Documents de l'Arxiu de la Corona d'Aragó (1429-1444), Valencia, Edicions 3i4, 2005, pp. 307 y 358; Miguel Navarro Sorní, "La promoción eclesiástica de Rodrigo de Borja: estrategia nepotista y política dinástica de Calixto III", en Paulino Iradiel, y José María Cruselles (dirs.), De València a Roma a través dels Borja, Valencia-Roma, Generalitat Valenciana-Ministero-Roma nel Rinascimento, 2006, pp. 72-75. 
reservada a su sobrino, y gracias a una bula de Nicolás V expedida al efecto, Lluís Joan pudo posesionarse de ella en abril de 1448. El rey no dejó de exigir su contraprestación, reclamando al cardenal 2.000 ducados por la provisión de las dos canonjías concedidas a sus sobrinos Milà y Borja, recordándole que si se negaba a pagar debería renunciar a ellas (1.II.1449) ${ }^{6}$.

Debió ser en 1450 cuando Alfonso de Borja hizo venir a Roma a sus cuatro sobrinos - los hermanos Pere Lluís y Rodrigo de Borja, junto con Lluís Joan y su hermano Pere del Milà- con la idea de formar su propia clientela catalana-aragonesa que le ayudase en su ministerio pontificio y perpetuase el patrimonio económico familiar ${ }^{7}$. Rodrigo y Lluís Joan fueron destinados a la carrera eclesiástica y su educación fue encomendada al humanista Gaspare da Verona, que tenía en Roma una prestigiosa escuela frecuentada por estudiantes pertenecientes a familias representativas de la ciudad o formaban parte del séquito de eminentes prelados, como Gabriele Marcello, pariente del cardenal Pietro Barbo, familiares del cardenal Luis d'Albret, o jóvenes destinados a tener un papel relevante en el ámbito cultural romano como Aldo Manuzio, Marcantonio Coccio "Sabellico", Giovanbattista Valentini "il Cantalicio" que mantendrá estrechos vínculos con los Borja, y muchos otros estudiantes extranjeros que superaban en número a los romanos ${ }^{8}$. Allí se pusieron de manifiesto las excelentes cualidades de Rodrigo, al cual Lluís Joan "apenas se le puede comparar, pues, aunque es su hermano [en realidad su primo] no posee la elocuencia, la presencia, ni la afabilidad del vicecanciller".

Más adelante, el poderoso cardenal envió a sus sobrinos a Bolonia, donde C. Piana documenta su presencia en los primeros años de la década de $1450^{9}$.

6.- C. López Rodríguez (dir.), Diplomatari Borja. 4, pp. 149-151 (doc. 98).

7.- Miguel Navarro Sorní, Callisto III. Alfonso Borgia e Alfonso il Magnanimo, Roma, Roma nel Rinascimento, 2006, pp. 159-160. Aunque este autor, como otros, dan la fecha de 1449 como orientativa del traslado de la parentela, en el caso de Milà habría que tener en cuenta las letras apostólicas datadas el 22 de agosto de 1450, en que se califida de joven tonsurado residente en Valencia y aspirante a la canonjía que acaba de vacar en la catedral de Lérida; Josep Lladonosa PuJol, Manuel de Montsuar: 1410-1491: la historia de un gran carácter al servicio de las instituciones leridanas, Lérida, ImprentaEscuela provincial, 1950, p. 51.

8.- Paolo Viti, "Gaspare da Verona”, en Dizionario Biografico degli Italiani, vol. 52, Roma, Treccani, 1999, pp. 466-470.

9.- Se decantan por las fechas más tempranas Celestino PIANA, Nuovi documenti sull'Università di Bologna e sul Collegio di Spagna, vols. I-II, Bolonia, Publicaciones del Real Colegio de España, 1976, ad indicem; Miguel Navarro Sorní, "Registro de Rodrigo de Borja como doctor e Derecho Canónico por la Universidad de Bolonia”, en Mariano González Valdoví y Vicent Pons Alòs (coords.), El hogar de los Borja: 2000 any Borja. Catálogo de la exposición (Xàtiva, Museu de l'Almodí, antic Hospital Major, del 16 de diciembre de 2000 al 28 de febrero de 2001), Valencia, Generalitat de Valencia, 2001, pp. 280-281; Juan NADAl CAÑEllas, "La permanencia de Rodrigo de Borja (Alejandro VI) en el Estudio de Bolonia, según los documentos originales", Acta historica et archaelogica mediaevalia, 27/28 (2008), pp. 173-205. 
Allí Rodrigo figura como testigo en dos actas notariales de nómina de procuradores por parte de un cierto Gabriel Rovira de Girona (7.VIII.1452), y en 1453 es Lluís Joan, recién nombrado obispo de Segorbe, quien designa como procuradores para los asuntos materiales de su diócesis a su hermano Pere y, para los espirituales, a su tío el cardenal (9.III.1453) ${ }^{10}$. Durante este tiempo, el prelado residió en una casa contigua a la capilla de San Mamas, no lejos de las sedes del Estudio de Derecho, gozando de mayor holgura económica que su primo Rodrigo por pertenecer a una familia mejor asentada.

El cardenal Borja impulsó con empeño la carrera beneficial de Lluís Joan: en junio de 1449 le otorgó una canonjía en la catedral de Valencia que fue obstaculizada por el gobernador del reino de Valencia - Juan de Aragón-y fue reabierta gracias a la intervención de Alfonso el Magnánimo que necesitaba el apoyo del cardenal en la concordia que estaba negociando con el clero de sus reinos. Aprovechando su posición de ventaja, Alfonso de Borja también obtuvo del pontífice con el consentimiento del rey el deanato de la colegiata de Játiva (30.IX.1450) para Lluís Joan — que debió ceder su canonjía de la Seo setabense a Rodrigo- y una canonjía en Lérida con dispensa de residencia (27.X.1450) ${ }^{11}$, cuyas rentas percibía a través de una nube de procuradores valencianos y catalanes nombrados por su tío ${ }^{12}$. De esta manera el cardenal ponía en manos de la familia los beneficios de su tierra natal. En la comunicación que envió al cabildo setabense afirmaba que, de ese modo, la iglesia en la que había recibido las aguas del bautismo tendría entre su clero a dos sobrinos suyos, a los que consideraba como hijos, con lo que buscaría con mayor fervor la exaltación de esa iglesia ${ }^{13}$. Para salvaguardar los beneficios de posibles competidores, Nicolás V le otorgó, a suplicación suya, reservas pontificias que fueran en perjuicio de las prerrogativas a él concedidas.

Finalmente Lluís Joan recibió la administración del obispado de Segorbe (29.I.1453) y de Santa María de Albarracín, vacante por fallecimiento del obispo Gispert Pardo de la Casta, con ciertas restricciones por la edad ${ }^{14}$. El

10.- Ibídem, pp. 181-182.

11.- Lluís Joan tuvo que competir con el candidato de cabildo- Manual de Montsuar- por la canonjía ilerdense, remitiendo las cartas apostólicas a través de su procurador Francesc Coll de Sanç (22. VIII.1450) que la obtuvo para su señor dos meses después (27.X.1450). Lluís Joan entró en posesión de la mísma el 21 de enero de 1451 y el 26 pagaba las 20 libras de derecho ad capam; LLADONOsA Pujol, Manuel de Montsuar, pp. 50-52.

12.- Vicent Pons Alòs, Cardenales y prelados de Xàtiva, p. 58.

13.- Miguel Navarro Sorní, La promoción eclesiástica de Rodrigo de Borja, pp. 72-75 y 77-78.

14.- Joaquín Lorenzo Villanueva, Viaje literario a las iglesias de España, vol. III: Segorbe, Madrid, Real Academia de la Historia, 1804, pp. 78-79; Enrique Flórez, España Sagrada, vol. XLVII, Madrid, Real Accademia de la Historia, 1850, pp. 84-87; Peregrín Luis Llorens RaGA, Episcopologio de la 
cardenal obtuvo el consentimiento regio a cambio de ceder a Berenguer de Sos, clérigo de Barcelona recomendado por el rey, el deanato de la colegiata setabense y la canonjía valentina que poseía su sobrino. En la pugna por Segorbe intervino el propio hermano de Lluís Joan, Pere del Milà, que prestó al rey 7.000 ducados para apoyar la provisión, con promesa de restituírselas si no se llevaba a efecto (23.I.1453) ${ }^{15}$. Alfonso el Magnánimo se puso manos a la obra escribiendo a Nicolás $\mathrm{V}$ y al colegio cardenalicio recomendándole para Segorbe frente a las pretensiones del cabildo y la oligarquía de la ciu$\operatorname{dad}^{16}$. Dos años después Lluís Joan fue nombrado obispo y destinó como vicario suyo al obispo de Doria (Cerdeña), Juan Anadón, que gobernó con sus oficiales Fernando Fraile y Juan Marqués. De esta época se ha conservado la matriz de su bello sello episcopal, con la imagen sedente de la Virgen María en un trono ricamente decorado en la mitad superior, y en la mitad inferior las armas del prelado timbradas por la mitra: escudo partido con el buey pasante (Borja) en la mitad de derecha y un milano (Milà) en la zona superior, mientras un león rampante ocupa la zona inferior de la izquierda, con la leyenda "LUDOVICI - IOHANIS - DEL - MILA - EPS - SEGROBRICEN - ET ALBARRZIN"17.

Pertrechado por tal cantidad de beneficios y mientras culminaba sus estudios en Bolonia, el joven Milà dio forma a una casa cada vez más nutrida de servidores. Nombró como procuradores en la Curia a su tío el cardenal, al juez pontificio Bernat Rovira y al médico Pere Climent; en la diócesis valentina al canónigo y vicario general Antoni Bou y al oficial episcopal Jaume Sala; y en la diócesis de Lérida al doctor en leyes, Juan de Altavit ${ }^{18}$, al canónigo y vicario general Ramón Rossell, a los canónigos Joan Secastella y Vicent Sopeira y al beneficiado Pere Cardona, todos ellos familiares suyos $(14 . X .1450)^{19}$.

diócesis de Segorbe-Castellón, vol. I, Madrid, Instituto Enrique Flórez, 1973, pp. 228-236; Francisco de Villagrasa y Teruel, Antigüedad de la Iglesia Catedral de Segorbe y catálogo de sus obispos (1664), ed. de Magín Arroyas Serrano, Vicent Gil Vicent, Valencia, Fundación Bancaja, 2001, pp. $158-161$.

15.- C. López Rodríguez (dir.), Diplomatari Borja. 4, p. 170 (doc. 116).

16.- María Milagros Cárcel Ortí y Vicent Pons Alós, "El clero valentino en la época de los Borja", en P. Iradiel, y J. M. Cruselles (dirs.), De València a Roma, pp. 239 y 241-242.

17.- Martín Almagro Basch, "Un curioso sello episcopal de Albarracín”, Teruel, 12 (1954), pp. 149-155.

18.- J. Lladonosa Pujol, Manuel de Montsuar, p. 136.

19.- C. Piana, Nuovi documenti sull'Università di Bologna, ad indicem. 


\section{De la legación de Rávena a la PÚRPURA CARDENAlicia}

La elección pontificia de Calixto III en 1455 tuvo importantes consecuencias en la vida de sus dos sobrinos, que regresaron inmediatamente a Roma para asistir a la coronación. El nuevo papa nombró a Lluís Joan vicario general y gobernador de Bolonia en sustitución del cardenal Besarión, ampliando su jurisdicción con facultades de legado a latere a los territorios de Rávena y la Romaña (13.VI.1455). Dos meses antes Calixto III había ordenado que los familiares de su sobrino fueran tenidos como familiares suyos (20.IV.1455) ${ }^{20}$, y no eran pocos, pues la comitiva en su viaje a Bolonia alcanzaba las cien personas (17.VI.1455). A pesar del mal tiempo, el 29 de junio la ciudad recibió con júbilo a los dos sobrinos, especialmente al joven gobernador - "hombre de encomiable vida y gentileza" ${ }^{21}$ — que entró por la puerta Mayor bajo palio de zendale azurro con los enviados del Senado romano, saliendo a su encuentro los ancianos y gonfalonieros. Además, las autoridades urbanas quisieron festejar al nuevo gobernador corriendo el Palio de San Pedro. Milà se alojó en el palacio episcopal con su numerosa comitiva (29.VI.1456), incluido su teniente el doctor Bartolomé Castillo, beneficiado de Segorbe ${ }^{22}$, superando ampliamente los treinta estudiantes que las autoridades locales exigieron a su primo Rodrigo en noviembre de 1455 para adecuarse a las condiciones del palacio Gregoriano en que se alojaba. Dado el vínculo de parentesco que ligaba a ambos eclesiásticos, la decisión de residir en alojamientos separados tan distintos podría deberse a dos opciones políticas diversas aunque convergentes donde Milà asumía un particular protagonismo ${ }^{23}$.

Desde el punto de vista académico ambos primos pudieron frecuentar las lecciones de derecho hasta el mes de agosto, a no ser que se incorporaran en octubre al nuevo curso académico ${ }^{24}$. El 18 de agosto de 1456 obtuvieron una dispensa de no haber estudiado Decreto en un año entero, lo que indica su aplicación al derecho civil durante este tiempo, sin descuidar otros intereses como la licenciatura en teología a la que asistió como protonotario apostólico Ludovico Borgia el 27 de abril de 1456. Como Rodrigo, debió frecuentar

20.- J. Rius SERra, Catalanes y aragoneses, p. 272.

21.- Cherubino Ghirardacci, Storia di Bologna, ed. A. Sorbelli, en Muratori, L. A. (dir.), Rerum Italicarum Scriptores, t. XXXIII, vols. I-III, Città di Castello, Editrice S. Lapi,1915, pp. 159-160.

22.- P. L. Llorens RaGa, Episcopologio de la diócesis, pp. 228-236.

23.- Giuseppe Mazzanti, "Rodrigo Borgia e lo Studium bolognese", en Ovidio Capitani, Maria Chiabò, Maria Consiglia De Matteis, Anna Maria Oliva (dirs.), La fortuna dei Borgia. Atti del convegno (Bologna, 29-31 ottobre 2000), Roma, Roma nel Rinascimento, 2005, p. 133.

24.- Francesco Giongi, "Rodrigo Borja allo studio di Bologna", en Atti e memorie per le provincia di Romagna, 8 (1890), pp. 159-195. Sobre la actividad académica del cardenal añádase a los trabajos citados el de Marta Pavón, "La formación de Alonso y Rodrigo de Borja", en Los Borja. Del mundo gótico al universo renacentista, Valencia, Generalitat Valenciana; Museu de Belles Arts, 2001, pp. 115-119. 
las lecciones del prestigioso canonista Andrea Barbazza y probablemente de Antonio Sampieri, Antonio della Volta y Battista Sampieri. Ambos obtuvieron la licenciatura a través de un rigoroso et privato examine gracias a una dispensa que les exoneraba del examen público, probablemente por su formación curial, laureándose con el parecer favorable de todos los doctores ${ }^{25}$.

Aunque algunos autores acusan de impericia al nuevo legado ${ }^{26}$, hay que tener en cuenta que Milà asumió el cargo en un momento de progresivo debilitamiento de la legación pontificia frente al reforzamiento del poder de la magistratura del Collegio dei Sedici y de la familia de los Bentivoglio dentro de ésta ${ }^{27}$. Su necesidad de congraciarse con los poderes fácticos se plasma en el permiso otorgado a los Sedici en septiembre de 1455 de ofrecer un regalo a Santi Bentivoglio con motivo de su matrimonio. En realidad, durante su legación no pudo hacer nada que no agradase a los Sedici o a los Bentivoglio, pues - como decía Givanni Battista Savelli- el gobernador pontificio que marchaba a Bolonia no era legatus sino ligatus, al estar gravemente imposibilitado de ejercer el gobierno que teóricamente se le reconocía ${ }^{28}$.

Lluìs Joan mantuvo su autoridad con un cierto protagonismo ceremonial. En agosto, dos meses después de su llegada, apoyó el nuevo proyecto de cruzada de su tío saliendo en procesión a San Petronio para dar lectura al breve pontificio y comenzar la predicación de la cruzada a cargo de un agustino venido de Roma ${ }^{29}$. Al año siguiente, el legado hizo sonar las campanas de la ciudad y encabezó la procesión con todas las reliquias para festejar la victoria de Belgrado (Hungría) contra los turcos de Mehmet II el 21 de julio de 1456. Aunque no podemos establecer sus vínculos directos con los fermentos religiosos de la ciudad, durante su gobierno se aprecia un particular impulso mendicante, con el traslado desde Ferrara a su ciudad natal (c. 1456) de la boloñesa Caterina de' Vigri que, con un grupo fervoroso de hermanas, fundó el convento de clarisas del Corpus Domini, donde llevó una vida ejemplar hasta el punto de ser precozmente beatificada ${ }^{30}$. A este fenómeno de movili-

25.- G. Mazzanti, Rodrigo Borgia, pp. 136-137; J. Nadal Cañellas, La permanencia de Rodrigo de Borja, pp. 190-191.

26.- Ludovico Pastor, Historia de los Papas: desde fines de la Edad Media, vol. II, Barcelona, Gustavo Gili, 1910, p. 442.

27.- Bernardo PIo, "Aspetti político-istituzionali di Bologna all'epoca di Alessandro VI", en La fortuna dei Borgia, pp. 118-119.

28.- Ibídem, pp. 119 y ss.

29.- Corpus chronicorum bononiensium: testo delle croniche, ed. de Albano Sorbielli, Città di Castello, Lapi, 1939, pp. 255 y 264.

30.- Augusto VASINA, "Chiesa e comunità dei fedeli nella diocesi di Bologna dal XII al XV secolo", en Paolo Prodi, y Lorenzo PAolini, Storia della Chiesa di Bologna, vol. I, Bolonia, Istituto per la storia della chiesa di Bologna, 1997, p. 184. 
dad de las órdenes religiosas también pertenece la introducción (c. 1455) de la orden de los gerolimiti que después de instalarse en San Cristoforo delle Muratelle se trasfirieron a la iglesia de Santa Ana.

A Calixto III no le retuvo la edad ni su supuesta incapacidad cuando decidió elevar a sus dos sobrinos a la dignidad cardenalicia. El proyecto era de dominio público en noviembre de 1455 , pero fue en el consistorio de las Témporas de Adviento cuando el papa deslizó su propuesta ante la oposición del colegio cardenalicio, que no pudo vencer ni siquiera hablando personalmente con cada uno de los purpurados. Unos alegaban que los candidatos "eranno tri putti, ed era una vergogna a fargli cardinali"; otros se negaban a admitir a ultramontanos, es decir no italianos; y había quien consideraba que otras personas lo merecían en mayor medida ${ }^{31}$. Sin embargo, al acercarse la Cuaresma de 1456 el papa retomó la idea incluyendo en la nómina cardenalicia a algunos candidatos de los príncipes que, al alarmar a los cardenales, éstos se darían por satisfechos con la elevación de unos pocos, aunque fueran los sobrinos del papa.

Aunque en el consistorio del 20 de febrero se dijo que no se había elegido a ningún cardenal, en realidad se había concedido el capelo a Rodrigo, Lluís Joan y a Jaime de Avis —hijo del infante Juan de Portugal- con el consenso unánime de los presentes (20.II.1456), que no pudieron ocultar su recelo hacia aquellos tres jóvenes "de óptima índole" que no sumaban la edad de un sólo cardenal ${ }^{32}$. Lluís Joan ya era presbítero pero Rodrigo y Jaime de Avis eran diáconos. La promoción se mantuvo en secreto por temor al despecho del rey de Nápoles y el duque de Milán que habían sido burlados en sus demandas cardenalicias, y además, los cardenales tenían la aviesa intención de no reconocerlos si el papa moría antes de su publicación. De todas formas, conviene precisar que su oposición no se basaba en la calidad moral de los elegidos, sino en su juventud o en sus orígenes humildes pues - como señala el cronista castellano - el papa "pospuso todo al cuidado de sublimar a sus jóvenes sobrinos, hijos de sus hermanas y de padres bajísimos, y de carácter nada glorioso ellos mismos, al honor cardenalicio" 33 . Alfonso el Magnánimo reaccionó airadamente acusando al pontífice de practicar un nepotismo vergonzoso al tiempo que se negaba a reconocerle como soberano

31.- M. Navarro Sorní, Callisto III, pp. 473-474.

32.- "Adeo iuvenes omnes, quamvis indolis optimae, ut non ab re ioco dixerint aliqui vix annos tres cardinales natos qui uni sufficerent”; Pío II, Commentaries, ed. M. Meserve y M. Simonetta, vol. I, Cambridge, Harvard University Press, 2003, pp. 148-149.

33.- Alonso de Palencia, Gesta hispaniensia ex annalibus suorum dierum collecta, ed. de Brian Tate y Jeremy Lawrance, vol. I, Madrid, Real Academia de la Historia, 1998-1999, p. 186. 
de Nápoles amenazando su proyecto dinástico ${ }^{34}$. A los recelos del monarca se añadía la promoción de Pere Lluís Borja, nombrado en aquellas fechas capitán de los ejércitos pontificios con el propósito de entregarle en un futuro no muy lejano el vicariato de Benevento y Terracina, y finalmente el mismo reino de Nápoles.

Los dos nepotes pudieron desplazarse a Roma en el mes de octubre para asistir al consistorio en el que Lluís Joan recibió el título de los Santos Cuatro Coronados que antiguamente ostentaba su tío. Los dos nuevos cardenales se erigían entonces en el núcleo duro de la clientela catalana-aragonesa de un pontífice cada vez más alejado de la tutela de Alfonso el Magnánimo y empeñado en construir un patrimonio familiar eclesiástico en los territorios del reino de Valencia. Sin embargo, no iba a ser tan fácil. El enfrentamiento con el rey de Aragón por impulsar un futuro concilio en 1456, provocó el bloqueo de los nombramientos episcopales en la Corona de Aragón ${ }^{35}$. De ahí que el papa echara mano de provisiones extra-ibéricas para sostener a sus sobrinos; Lluís Joan recibió la reserva de un beneficio en la abadía boloñesa de Santa Cecilia de Comaria (25.V.1456), el permiso de conferir los beneficios vacantes en su obispado los meses alternos (7.VI.1456), ciertas expectativas para Saboya (24. IX.1456), y la reserva de beneficios que vacaren en el territorio de su legación y en los dominios del duque de Milán hasta alcanzar la suma de 7.000 florines (30.XII.1456) ${ }^{36}$. En virtud de estas concesiones recibió en fecha incierta la encomienda de las abadías de Grasano y San Iannuario en el Piamonte ${ }^{37}$. Durante este tiempo, Lluìs Joan intervino en el conflicto que enfrentó al papa con algunos capítulos catedralicios y entidades eclesiásticas de la Corona de Aragón sobre el pago de la décima en los primeros meses de 1457. No estaba claro que su recaudación estuviera a cargo de los colectores o los cardenales que poseían estos beneficios, como Milà, que poseía el episcopado de SegorbeAlbarracín, cuyo capítulo apelaba a ciertos privilegios de exención ${ }^{38}$.

El 7 de enero de 1457 regresó a Bolonia investido de amplias facultades civiles y criminales, mientras el papa seguía llenando sus arcas con una montaña de beneficios: el arcedianato de Bolonia (27.I.1457), la prepositura de San Marta Extramuros de Novara (17.II.1457) — con renta de 780 ducados

34.- Alan Ryder, Alfonso el Magnánimo, rey de Aragón, Nápoles y Sicilia (1396-1458), Valencia, Edicions Alfons el Magnànim, 1992, p. 501; P. Iradiel y J. Mª Cruselles, El entorno eclesiástico de Alejandro VI, pp. 40-41.

35.- M. Navarro Sorní, Callisto III, pp. 216-221.

36.- J. Rius Serra, Catalanes y aragoneses, pp. 272-273; M. Navarro Sorní, Callisto III, p. 218.

37.- Alfonso Chacón, Vitae et res gestae Pontificum romanorum et S.R.E. Cardinalium, vol. II, Roma, Typis Vaticanis, 1677, cols. 989-990.

38.- M. Navarro Sorní, Callisto III, p. 443. 
anuales-, los monasterios benedictinos de los Santos Víctor y Corona y San Jenaro en la diócesis de Vercelli (26.II.1457), valorados respectivamente en 300 y 200 florines; más adelante le otorgó el monasterio de San Breme en la diócesis de Pavía (10.VII.1457), el hospital de los pobres de Puente Rheni - cerca de Bolonia- (23.X.1457), el monasterio de San Benigno de Muleyo en Vercelli (17.II.1458), los monasterios de Durano y San Mercurial en Forli $(31 . V .1458)^{39}$. Ninguno de estos beneficios se hallaban en el reino de Aragón, donde Alfonso el Magnánimo censuraba la obsesión del papa por "impinguare questi soy nepoti" (26.II.1457). De ahí que el fallecimiento del monarca (27. VI.1458) hiciera pronunciar al pontífice el salmo CXXIII: "laqueus contritus est, et nos liberati sumus". Al día siguiente Calixto III convocó un consistorio extraordinario en que entregó la sede de Valencia a su sobrino Rodrigo de Borja, cediendo los beneficios que dejaba vacantes a su primo Lluís Joan: concretamente, la dignidad de sacristán en la catedral de Valencia, el deanato en la colegiata de Játiva y la iglesia parroquial de Cullera, que le reportaban anualmente 1.000 libras turonesas parvas (30.VI.1458) ${ }^{40}$.

Para compensar las escasas rentas de Segorbe y tras el intento frustrado de promoverle a la sede de Burgos (9.III.1457), Calixto III le asignó una pensión de 2.000 ducados sobre los frutos de la mesa episcopal de Gerona, sede que acababa de entregar a Cosme de Montserrat contra el parecer de Juan II de Aragón ${ }^{41}$. Como advierte Navarro Sornì, esta complicada maniobra que soslayaba el recurso más sencillo de entregar a Lluís Joan la sede de Gerona y a Cosme la de Segorbe, obedecía a la estrategia nepotista del primer papa Borja, consistente en consolidar una dinastía episcopal en los territorios del reino de Valencia: los obispados poseídos por sus sobrinos en las tierras del Reino no debían salir de su poder, para que después pasaran a otros miembros de la familia ${ }^{42}$. Esta política no evitó ciertas tensiones entre los miembros del clan, pues Milà hizo causa común con Cosme cuando el rey aragonés intentó colocar en Gerona a su candidato con la ayuda de Rodrigo de Borja, a quien prometió la libre posesión de Valencia si le apoyaba. El conflicto duró un año entero hasta que la diplomacia del vicecanciller y la tenacidad

39.- J. Rius SERra, Catalanes y aragoneses, pp. 272-273.

40.- M. Navarro Sorní, "Un obispo frustrado de Segorbe, Francesc Ferrer, y el enfrentamiento del cardenal Lluís del Milà con Juan II de Aragón”, en Homenaje al profesor R. Rodríguez Culebras, Valencia, Fundación Dávalos-Fletcher, 2004, p. 43.

41.- Santiago Sobrequés I VidAL, "L'afer de les diocesis catalanes vacants en 1457-1460 i la politica italiana de Joan II", en IX Congresso di storia della Corona d'Aragona (Napoli, 11-15 aprile 1983). La Corona d'Aragona e il Mediterraneo: aspetti e problemi comuni da Alfonso il Magnanimo a Ferdinando il Cattolico (1416-1516), vol. III, Palermo, Società Storia Patria Napoli, 1984, pp. 328, 335 y 339.

42.- M. Navarro Sorní, Un obispo frustrado de Segorbe, pp. 43-50; ID., Callisto III, p. 221. 
de Juan II lograron convencer a Milà de que renunciara a los dineros de Gerona por una pensión sustitutoria en el verano de 1459. Años más tarde, el obispo gerundés Joan Margarit atribuirá a esta política de componendas con los prelados absentistas el origen de los descontentos que suscitaron la guerra civil en Cataluña ${ }^{43}$.

\section{Magnificencia y RePresentaciones SaCras al SERVicio de Pío II}

Lluís Joan se encontraba en Bolonia cuando recibió la noticia de la enfermedad de su tío. Partió el 4 de agosto con dos ciudadanos boloñeses, pero la muerte del papa le sorprendió de camino, llegando a Roma cinco días después del deceso (11.VIII.1458). Tanto él como Rodrigo sobrevivieron a la caza de catalani que se desencadenó y — aunque no hay pruebas categóricas $^{44}$ - tal vez encargó junto a éste el sepulcro de mármol que albergaría los restos de Calixto III en la capilla vaticana de Santa Maria delle Febbre, atribuido al taller de Andrea Bregno ${ }^{45}$ o a ciertos artistas lombardos instalados en Roma ${ }^{46}$. Se trataría de uno de los primeros gestos documentados de la sensibilidad artística de un cardenal a quien se ha atribuido el famoso relieve de la Virgen con el Niño en alabastro de la catedral de Segorbe, que podría ser donación suya o de su hijo el canónigo, y no de Rodrigo de Borja como se ha afirmado ${ }^{47}$.

En el cónclave celebrado en agosto, los dos purpurados sostuvieron la candidatura de Pío II, especialmente Milà que le votó desde el primer escrutinio animado por los agentes milaneses ${ }^{48}$. El nuevo pontífice no olvidaría este apoyo mostrando durante su mandato una especial confianza en el prelado valenciano. $\mathrm{Al}$ año siguiente, éste se encontraba entre los ocho cardenales que

43.- Robert Brian TAte, Joan Margarit i Pau cardenal i bisbe de Girona: la seva vida i les seves, Barcelona, Curial Edicions Catalanes, 1976, p. 61.

44.- Marià Carbonell i BuAdes, "El sepulcre de Calixt III Borja: hipòtesi atributiva. Una contribució al Vè centenari de la mort d'Andrea Bregno", Revista Borja. Revista de l'IIEB, 1 (2006-2007), pp. 51-62 [http://www.elsborja.org/revista.php].

45.- Ximo Company i Climent, Alexandre VI i Roma: les empreses artístiques de Roderic de Borja a Italia, Valencia, Edicions Tres i Quatre (3i4), 2002, pp. 118-120.

46.- Daniela Gallavotti Cavallero, "Sculture quattrocentesche provenienti dal vecchio San Pietro: il monumento funebre di Callisto III Borgia", en Sergio Rossi y Stefano VALERI (dirs.), Le due Rome del Quattrocento: Melozzo, Antoniazzo e la cultura artistica del'400 romano, Roma, Lithos, 1997, pp. 236-241.

47.- Marià CARbonell i Buades, "Rodrigo de Borja, cliente y promotor de obras de arte. Notas sobre la iconografía del apartamento Borja del Vaticano", en Mario Menotti, Los Borja, Valencia, Obra Social i Cultural, Bancaixa, 1992, p. 419.

48.- Pío II, Commentaries, pp. 194-195 y 400; L. Pastor, Historia de los Papas, vol. III, p. 61. 
acompañaron al pontífice a la dieta de Mantua convocada para hacer frente a la expansión otomana: el 18 de abril se hallaba en Siena ${ }^{49}$, el 9 de mayo participó en el solemne ingreso de Pío II en la ciudad de Bolonia, y pocas semanas después se hallaba en Ferrara alojado en el palacio del señor de Carpi (22.V.1459) ${ }^{50}$. Milà entró en Mantua cabalgando "con gran pompij” y escoltado por un séquito de 90 o 100 personas a pie y a caballo; una comitiva inferior a las 200 o 250 monturas que llevaba Rodrigo de Borja. Para entonces nuestro cardenal parecía tan avejentado que se le atribuían diez años más de los que contaba - 38 años, cuando en realidad rondaba los 26 - destacando su delgadez y fealdad pues "era magro e de pocho e brutto aspetto" 51.

Lluís Joan participó en el Congreso (1.VI.1459) y asistió a la prestación de obediencia de los embajadores de Juan II de Aragón por el reino de Sicilia que el papa acababa de otorgarle ${ }^{52}$. Sin embargo las relaciones con el rey se vieron comprometidas por la vacante de la diócesis de Lérida que el cardenal - con la aquiescencia de Pío II - pretendía permutar por la sede menos rica de Segorbe (7.X.1459), abandonando así el antiguo proyecto de su tío sobre las sedes levantinas, y aumentar sus rentas con una pensión sobre la mitra de Vich (12.X.1459). Juan II intentó disuadirle ofreciéndole el obispado de Mallorca o el de Palermo a través de la mediación de Rodrigo, pero Milà sólo estuvo dispuesto a renunciar a Lérida a cambio de una compensación económica de 2.000 florines anuales que el monarca quiso reducir a la mitad. Al final cedió el rey y Lluís Joan se hizo con la sede ilerdense previa renuncia a la sede de Segorbe (12.XI.1459), recibiendo una pensión anual de 1.000 florines de oro aragoneses de ésta sede episcopal y una pensión similar de las rentas de Vicenza ${ }^{53}$. La noticia se transmitió al cabildo el 9 de octubre de 1460, y el prelado — que debió recibir entonces la consagración episcopaltomó posesión el 23 de febrero del año siguiente a través del procurador Juan de Alcañiz ${ }^{54}$.

49.- L. Pastor, Historia de los Papas, vol. III, p. 99.

50.- Bernardino Zамвотті, Diario Ferrarese dall'anno 1476 sino al 1504, ed. de Giuseppe Pardi, vol. I, Bolonia, Nicola Zanichelli, 1937, p. 41.

51.- Andrea Schivenoglia, Cronaca di Mantova dal MCCCCXLV al MCCCCLXXXIV, en C. D'ArCo (ed.), Raccolta di cronisti e documenti storici lombardi inediti, vol. II, Milán, Francesco Colombo Editori, 1857, p. 137; cfr. Rodolfo SignORINI, "Alloggi di sedici cardinali presenti alia Dieta", en Arturo Calzona (ed.), Il sogno di Pio II e il viaggio da Roma a Mantova. Atti del Convegno internazionale, Mantova, 13-15 aprile 2000, Mantua, Leo S. Olschki, 2003, Florencia, 2003, pp. 342-343 y 380.

52.- Jerónimo Zurita, Anales de la Corona de Aragón, vol. VII, Zaragoza, Institución Fernando el Católico, 1977, p. 232.

53.- Peter DE Roo, Material para una historia del papa Alejandro VI, sus deudos y su tiempo, trad. de V. Pascual y Beltrán, vol. I: La Casa de Borja. Pub. Academia Borja del Centro de Cultura Valenciana, Valencia, 1952, pp. 74-79 y 81-84; V. Pons Alòs, Cardenales y prelados de Xàtiva, pp. 58-59.

54.- J. L. Villanueva, Viaje literario a las iglesias, vol. XVI, p. 43. 
Pío II no se limitó a apoyar su promoción episcopal. En abril de 1460, mientras se ausentaba de Roma, le encargó - junto a los cardenales Ludovico Scarampo, Alain de Coetivy y Juan de Torquemada - la misión de concertar al general de las tropas pontificias Napoleone Orsini con Ferrante de Nápoles para defender el reino ante las pretensiones de Juan de Anjou ${ }^{55}$. Sin embargo, el cardenal valenciano no parecía mostrar mucho entusiasmo por el gobierno de la Iglesia. El 21.VI.1461 anunció su propósito de marcharse a Siena huyendo de los calores romanos ${ }^{56}$, y en otoño se desentendió de la promoción cardenalicia a pesar de las insistentes consultas del papa ${ }^{57}$. Durante estos meses vigilaba las intromisiones de su primo el vicecanciller en su diócesis de Lérida, como ocurre el 6 de octubre en que le escribe quejándose de haber provisto una canonjía sin haberle consultado, y le envía a Gaspar Sanç, "consanguineo meo", para informarse ${ }^{58}$. El vicecanciller le contestó enseguida aclarándole que el beneficiado era Bartomeu Vallescar, antiguo servidor de Calixto III $^{59}$.

Ambos cardenales no se limitaron a distribuir beneficios entre los miembros de su clientela. En marzo de 1462 Lluís Joan contaba con un "bellissimo palazo" en Roma comparable al que estaba construyendo su primo en la antigua Cancillería, hoy palacio Sforza-Cesarini ${ }^{60}$. Se trata de un importante precedente del proyecto residencial que el cardenal desarrollará más tarde en Albaida. No fue su única empresa artística en la Ciudad Eterna, pues entre 1455 y 1458 impulsó labores de embellecimiento en la basílica de los Santos Cuatro Coronados, iniciadas por su antiguo titular, Calixto III, y centradas en la reparación de puertas, escaleras, ventanas y muebles del palacio y la capilla episcopal ${ }^{61}$.

55.- Vease el despacho de Vizenzo della Scalona a Ludovico Gonzaga, 17 abril 1460; en Isabella LAZzARINI (dir.), Carteggio degli oratori mantovani alla corte sforzesca (1450-1500), vol. II: 1460, Ministero per i beni e le attività culturali, Roma, 2000, pp. 196-197.

56.- L. Pastor, Historia de los Papas, vol. III, p. 152.

57.- J. GoÑ G Gaztambide, Mila, Luis Juan de, p. 490.

58.- La carta, probablemente autógrafa, del cardenal de Lérida, está datada en Siena el 9 de octubre de 1461 e iba dirigida a un "reverendissime pater" consanguineo suyo, identificable con su primo Rodrigo; Biblioteca Nacional de España (Madrid), Ms. 4026, f. 24, donde figura como exemplum o modelo de escritura. Debo esta información a la generosidad y el conocimiento documental de Maria Toldrà.

59.- La respuesta de Rodrigo a Lluís Joan está datada en Roma el 19 de octubre del mismo año; en Ibidem, f. 24v.

60.- David Sanderson Chambers, Renaissance Cardinals and Their Worldly Problems, Aldershot, Variorum, 1997, ad indicem.

61.- Véanse los registros documentados entre el 6 de noviembre de 1455 y el 13 de mayo de 1458; Eugène MünTZ, Les Arts à la cour des papes pendant le XVe et le XVIe siècle, Hildesheim, Georg Olms, 1983, pp. 201-202. 
Un momento significativo y desconocido en las biografías del cardenal es su participación en la magnífica celebración del Corpus Christi que Pío II protagonizó en Viterbo en $1462^{62}$. En aquella competición artística y devocional en que el papa encargó a los cardenales la decoración de los diferentes tramos de la procesión, Milà se ocupó de cubrir la parte final, es decir, la plaza que se abría ante la catedral de San Lorenzo (Piazza del Duomo) y llegaba hasta el palacio episcopal. El cardenal decoró este espacio con tapices pintados o estampados suspendidos de grandes vigas ligadas con cuerdas que atravesaban ambos lados de la plaza, donde dispuso un altar, que tenía a su derecha el trono del papa con los sitios cardenalicios, y a la izquierda los asientos de los obispos, protonotarios y abades. Se trataba de una construcción de madera semejante a la capilla vaticana de tiempos de Pío II, es decir, la antigua de San Nicolás decorada por fra Angelico, con forma de aula y ábside al fondo ${ }^{63}$. A un lado de la plaza se erigió en posición elevada el sepulcro de la Virgen María, y más arriba, a la altura de los tejados de las casas, se escenificó el Cielo con Dios sentado en majestad, rodeado de ángeles, santos y astros luminosos.

Los Comentarii de Pío II describen la magnífica ceremonia, deteniéndose en el misterio de la Asunción de la Virgen representado en la zona adjudicada al cardenal del Milà ${ }^{64}$. Finalizada la Misa y tras la bendición del papa, un niño disfrazado de ángel anunció el inminente prodigio: de pronto se abrió el sepulcro y apareció una espléndida niña que elevada por los ángeles dejó caer su cinturón y fue alzada hasta la gloria del Cielo. El Hijo salió a su encuentro, la besó en la frente y la presentó al Padre colocándola a su derecha. Después, una multitud de espíritus celestes rompieron a cantar y a hacer sonar los instrumentos musicales mostrando el júbilo de la gloria celeste. La multitud reunida era tal que el papa invitó al pueblo a ocupar los prados que se extendían tras el palacio pontificio y desde allí les bendijo concediendo la indulgencia plenaria de los pecados.

El cardenal del Milà también se ocupó de adecentar el antiguo palacio, donde ofreció a Pío II y a los cardenales un banquete "como suelen celebrar los reyes", tasado en 500 ducados ${ }^{65}$. Las estancias se habían decorado "con

62.- Fabrizio Cruciani, Teatro nel Rinascimento. Roma 1450-1550, Roma, Bulzoni, 1983, pp. 71 y 74-76.

63.- Simonetta VALTieri, "Tutta una città come luogo teatrale per il Corpus Domini del 1462. Una memorabile festa organizzata da Pio II a Viterbo", Biblioteca e Società, Viterbo, 1980, pp. 26 y 30.

64.- Pio II, I commentari, ed. de Mino Marchetti, Siena, Cantagalli, 1984, ad indicem.

65.- Se trata del testimonio del cronista viterbense Niccolò Della Tuccia, Cronica di Anzillotto viterbense (...) continuata da Nicola (...) della Tuccia sino all'anno mcccclxxiii, ed. F. Cristofori, Roma, 1890, pp, 134-139. 
gran magnificencia" (cardinalis cuncta magnifice exornavit) aprovechando el cortile que se apoyaba sobre altas arcadas con una fuente en su centro adornada "con oro y plata". También se cubrieron los muros con preciosos tapices representando "antiguas historias memorables que mostraban el exquisito ingenio del artista que los había elaborado"; sin olvidar las cámaras y salas adornadas con "panni razi e di seta di gradissimo valore". Para el banquete, se usó vajilla pesada de oro y plata, y un grupo de cantores hizo sonar sus liras. Pío II pondera en sus Comentarii su excelente organización, la agradable conversación (grata colloquia) o las bromas honestas (sales honestate conditi) que hicieron correr las horas. De los testimonios coetáneos se deduce la capacidad de nuestro cardenal de formar equipos de trabajo, contratando a artesanos, albañiles y artistas que levantaron los grandiosos escenarios del drama sacro y la residencia palacial. Ello pone de manifiesto no sólo la sensibilidad artística y religiosa del prelado valenciano, sino su capacidad de implicarse en proyectos comunes del colegio cardenalicio participando activamente en la vida artística y espiritual de la Italia del Renacimiento.

\section{ENTRE LÉRIDA Y ROMA}

A pesar de la intensa actividad romana, el cardenal deseaba regresar a la península Ibérica. El enfrentamiento de Juan II con el Principado había llevado a su apogeo la guerra civil en Cataluña, donde Enrique IV había sido proclamado soberano por la Generalitat. El 16 de mayo de 1463 el nuevo monarca escribió a Milà y a Borja exponiendo la situación, defendiendo sus derechos al trono y suplicándoles que no proveyeran beneficios eclesiásticos a petición de Juan $\mathrm{II}^{66}$. No era una propuesta teórica pues, poco antes, su lugarteniente en Cataluña había exhortado a Lluís Joan a no vulnerar la jurisdicción civil incoando un proceso contra Simón García, abogado laico de Lérida, y por tanto no sometido a jurisdicción eclesiástica (30.IV.1463) ${ }^{67}$.

Pío II encargó entonces al cardenal valenciano que buscase por todos los medios el fin de las hostilidades en Cataluña (1.IX.1463) ${ }^{68}$, pero éste demoró su viaje varios meses hasta que - con la presencia alentadora del condestable de Portugal en tierras catalanas- decidió partir con una nueva recomenda-

66.- Jaume Sobrequés i CAllicó, Catálogo de la cancillería de Enrique IV de Castilla, señor del principado de Cataluña: (lugartenencia de Juan de Beaumont, 1462-1464), Barcelona, Consejo Superior de Investigaciones Científicas, 1975, p. 217 (doc. 1122).

67.- Ibídem, p. 193 (doc. 990).

68.- José María Pou i Martí, "Relacions del papa Pius II amb Joan II d'Aragó i els catalans", en Analecta Sacra Tarraconensia, 12 (1936), pp. 371-372 y 380-382. 
ción del papa en la que se suprimían las sanciones de la bula anterior y se enfatizaban las bendiciones en caso de llegar a una concordia (18.III.1464). Partió de Roma el 5 de abril de 1464 y en el mes de julio se encontraba en Lérida, donde llegó con las tropas reales para negociar la rendición de la ciudad asediada por Juan II. El cardenal intervino en las capitulaciones que pusieron fin a la guerra (6.VII.1464), extendiendo su actitud apaciguadora sobre el personal ausente, especialmente Manuel de Montsuar, vicario del anterior obispo de Lérida, presidente de la Generalitat de Cataluña y uno de los principales cabecillas de la rebelión ${ }^{69}$. Milà logró que adoptara una estricta neutralidad política cuando se refugió en Lérida en septiembre de 1464, y más adelante le restablecería en el oficio de vicario general gobernando ya Fernando el Católico ${ }^{70}$.

Al poco de llegar a la ciudad, el prelado juró las constituciones de su Iglesia en el palacio episcopal y recibió la prestación de homenaje del cabildo $\left(20\right.$. VII.1464) ${ }^{71}$. Poco después acogió las solicitudes de los regidores para reducir las insistentes peticiones del rey exigiendo hombres y dinero sin tener en cuenta la penuria que padecía la ciudad ${ }^{72}$. A él le tocó normalizar la vida eclesiástica y económica mediante reuniones permanentes con el cabildo en el palacio episcopal. Según Lladonosa, el prelado no defraudó las expectativas puestas en él, mostrándose con el personal eclesiástico y los ciudadanos clemente y generoso, presto a servirles en lo posible, a pesar de haber sostenido con los dirigentes de la ciudad alguna enojosa cuestión por intemperancia de sus familiares contra el primer paher mosén Nicolás Pou en su propio domicilio. El pueblo tampoco olvidó que gracias al cardenal pudo conservar el tesoro de sus franquicias y le mostró singular afecto en los comienzos de su pontificado en que residió en la diócesis ${ }^{73}$.

En 1466 se desplazó a Valencia con una escolta de 35 caballeros armados y fue recibido con todos los honores (5.VI.1466) ${ }^{74}$. En el palacio del obispo — situado en la calle Zaragoza - residía su madre Caterina, a la que llamaban "Milana", en una situación desahogada si tenemos en cuenta el robo de "or e argent e perles e coses de molta valua" que sufrió el 10 de enero de 1469; dato expresivo de la afición al lujo y el tren de vida que la familia habría alcanzado.

69.- J. Lladonosa Pujol, Manuel de Montsuar, pp. 217-223; ID., Manuel de Montsuar, President de Catalunya:1410-1491, Barcelona, Rafael Dalmau, 1962, pp. 51-52.

70.- Ibídem, p. 54.

71.- E. Flórez, España Sagrada, vol. XlVII, p. 86; J. Lladonosa Pujol, Manuel de Montsuar, p. 52.

72.- Josep Lladonosa Pujol, Història de la ciutat de Lleida, Barcelona, Curial, 1980, p. 131.

73.- J. Lladonosa Pujol, Manuel de Montsuar, pp. 223-224.

74.- J. SAnchis Sivera (ed.), Dietari del capellà, p. 286. 
$\mathrm{Al}$ año siguiente Lluís Joan volvió a Roma (10.II.1467), donde mantuvo una cierta distancia de los asuntos y de la estima de Paulo II. La peste difundida en la Urbe en julio de 1468 le obligó a marcharse con otros purpurados, instalándose en el monasterio cisterciense de San Salvatore sul monte Amiata (Toscana). Allí le escribió el cardenal Iacopo Piccolomini-Ammannati (14221479) alegrándose de su cercanía e invitándole a su residencia de Pienza (16. VII.1468) ${ }^{75}$. La relación es significativa pues en torno a Ammannati se reunía uno de los principales círculos humanistas y de difusión de manuscritos antiguos. El propio Iacopo, discípulo de Guarino de Verona y de Leonardo Bruni, y secretario privado de Eneas Silvio Piccolomini, el futuro Pío II, mantenía correspondencia con otros eclesiásticos españoles como Pedro González de Mendoza, el datario Francisco de Toledo y entre sus familiares se encontraba Rodrigo de Santaella ${ }^{76}$. En una misiva posterior, Ammannati informó a Lluís Joan de los últimos acontecimientos en Europa Oriental enviándole una copia de las cartas de Matías Corvino - rey de Hungría- sobre la reanudación de las operaciones militares contra el rey de Bohemia, Jorge Podiebrad ${ }^{77}$. Aunque no conocemos las respuestas, esta correspondencia es un interesante testimonio de los intereses que Milà debía compartir con el prestigioso cardenal, especialmente en la política de la Santa Sede ante la expansión otomana, uno de los objetivos que más había absorbido las fuerzas de Calixto III y Pío II.

En esta época el cardenal valenciano también debió relacionarse con el joven poeta de Amelia, Antonio Geraldini, desplazado a la península Italiana con su tío Angelo como agente diplomático de Juan II. Entre 1467 y 1468 Antonio le enderezó una oda encomiástica en versos líricos latinos — de rigurosa imitación horaciana ${ }^{78}$ - que se conserva en la colección de 23 poemas dedicados a Paulo II y a otros cardenales como Besarión o el propio Rodrigo de Borja ${ }^{79}$. El opúsculo viene precedido por el poema De pace per

75.- Iacopo Ammannati Piccolomini, Lettere (1444-1479), ed. P. Cherubini, Roma, Ministero per i Beni Culturali e Ambientali, 1997, pp. 1157-1158.

76.- Edith PÀszTor, "Ammannati, Iacopo", en Dizionario Biografico degli Italiani, vol. 2, Roma, Treccani, 1960, pp. 802-803.

77.- I. Ammannati Piccolomini, Lettere (1444-1479), vol. II, pp. 1158 y ss.

78.- Francesco BAUSI, "Antonio Geraldini”, en Enciclopedia Oraziana, vol. III, Roma, 1998, p. 243; ID., "Geraldini (Gerardini, Giraldini), Antonio", en Dizionario Biografico degli Italiani, vol. 53, Roma, Treccani, 2000, p. 322; Martin FrüH, Antonio Geraldini (†1488): Leben, Dichtung und soziales Beziehungsnetz eines italienischen Humanisten am aragonesischen Königshof: mit einer Edition seiner "Carmina ad Iohannam Aragonum”, Münster, LIT, 2005, pp. 14 y 54; a quien agradezco la amabilidad el haberme hecho llegar el texto del poema.

79.- El poema de Antonio Geraldini dedicado al Amplissimo domino Lodovico Joanni titulo Sanctorum Quatuor Coronatorum presbytero cardinali se halla en los carmina dedicados a Paulo II en BIBLIOteca Apostólica Vaticana, Vat. lat. 3611; recogido en Antonio Geraldini, Specimen carminum, ed. de B. Geraldini, Ameria, 1893, pp. 21-22; Jürgen Petersohn, Ein Diplomat des Quattrocento: Angelo Geraldini (1422-1486), Tübingen, Max Niemeyer Verlag, 1985, pp. 2 y ss. 
Paulum II Italiae reddita, datable en los primeros meses del 1468, donde se celebran los esfuerzos papales por unir a los príncipes cristianos frente a la amenaza otomana, objetivo de la misión diplomática de los Geraldini que sintonizaba con las preocupaciones del cardenal del Milà. En su oda dedicada a éste durante su encuentro en una villa de recreo, Antonio elogia su virtud (virtu[t]is specimen) y su ardua scientia con metáforas campestres, ponderando estas aptitudes como los lirios olorosos que decoran los campos, las vides el rodrigón que las sostiene o las fragrantes violetas sobre los prados; de ahí que condenar sus méritos al silencio sea tan injusto como abandonar a los héroes de la Antigüedad - Héctor, Aécides de Épiro, Ulises, Eneas y Rómulo- al olvido de la laguna Estigia, o confinar a los Césares al opaco Tártaro. Más allá de los tópicos laudatorios, conviene retener las dos cualidades que sobresalían en el cardenal: una honestidad moral que -en algunos aspectos- se deteriorará con el tiempo, y una sabiduría que debía ser el fruto más granado de su esmerada educación.

Lluís Joan permaneció algún tiempo más en Roma, pues el 15.X.1468 se le documenta en el consistorio cardenalicio ${ }^{80}$. Durante este período Juan II solicitó su ayuda para obtener algunas provisiones, como la concesión a sus nietos Juan y Alfonso del archidiaconado de Játiva, y el de Daroca con el priorato de Roda respectivamente (10.III. 1469) ${ }^{81}$. Milà recibió este tipo de encargos junto a su primo el vicecanciller Rodrigo de Borja, que mostraba más ganas de afincarse en Roma, pues Lluís Joan gozaba de mala salud y el clima romano le resultaba lo suficientemente adverso como para anhelar el regreso a la península Ibérica. Teodoro Llorente señala que un servidor suyo oriundo de Carrícola, en el valle de Albaida, le ponderó la virtud de sus aguas para sanar los padecimientos que le aquejaban, "vino a probarlas, y tan bien le sentaron, que no quiso volver a la Ciudad Eterna" 82 .

\section{La construcción de un estado señorial bajo Fernando el Católico}

El cardenal no permaneció mucho tiempo en Italia. A fines de 1469 asistió en representación de la diócesis de Lérida a las Cortes de Monzón convocadas por Juan II. Junto a su nuevo vicario, Manuel de Montsuar, el obispo de

80.- Paolo Cherubini, "Lettere concistoriali di Eugenio IV e Sisto IV. I. Nuovi documenti su Leonardo della Rovere nipote di Sisto IV e prefetto di Roma (con cinque lettere a Lorenzo de' Medici)", Bullettino dell'Istituto Storico Italiano per il Medio Evo, 102 (1999-2000), pp. 164 y 184.

81.- Jaume Vicens Vives, Historia crítica de la vida y reinado de Fernando II de Aragón, Zaragoza, Institución Fernando el Católico, 1962, p. 208.

82.- Teodoro Llorente, España en sus monumentos y artes, su naturaleza e historia, vol. II: Valencia, Barcelona, Editorial de Daniel Cortezo, 1889, p. 778. 
Lérida logró que aquellas Cortes fueran favorables a los intereses del cabildo y el gobierno de la ciudad, quienes recibieron el 22 de diciembre la feliz noticia de la derogación de la ley que a modo de veto mantenía el rey contra el colegio catedralicio ${ }^{83}$. La intensa actividad de aquellos meses exigió al obispo permanecer en Monzón. El 23 de enero de 1470 regresó a Lérida con su vicario, pero el 31 volvió a partir a la villa del Cinca donde intercalaba su intervención parlamentaria con visitas a la corte para recuperar las localidades de Alfés, Sunyer, Pellenes, Vallfogona y las tierras de los Sancliments para el capítulo catedralicio ${ }^{84}$.

Sin embargo los intereses del cardenal comenzaron a desplazarse al valle de Albaida, donde cada vez eran más frecuentes sus escapadas. En 1471 compró la villa a Beatriz Català de Valeriola, junto a los lugares cercanos de Carrícola, Bufali, Palomar, Benissoda y Adzaneta, que le permitieron crear la base territorial sobre la que materializar sus planes de fundar una sólida casa nobiliaria ${ }^{85}$. Se trataba de unos territorios alienados por Pedro IV de Aragón durante la guerra con Castilla, y que Juan II volvió a subastar en 1471 perdiendo el resto de la jurisdicción que le quedaba para afrontar los gastos de la guerra civil catalana. La compra desagradó a los habitantes de Albaida por la nueva alienación que suponía, y si el dominio del cardenal multiplicó los conflictos fiscales al menos atenuó las manifestaciones de violencia feudal que habían imperado en las últimas décadas ${ }^{86}$.

Lluís Joan comenzó entonces su proyecto edilicio más ambicioso: el palacio de Albaida, cuya primera fase constructiva debió desarrollarse entre 1471 y 1477, pues en este último año hizo donación de la baronía de Albaida a su hijo otorgándole el fortalitio seu dominali hospitio de la villa, es decir, la fortaleza o residencia señorial ${ }^{87}$, donde él mismo se hallaba retirado con toda su familia ${ }^{88}$. Una "familia" que, por otra parte no dejaba de crecer, pues

83.- J. Lladonosa Pujol, Manuel de Montsuar, pp. 253-254.

84.- Ibídem, p. 254.

85.- Vicent Terol i Reig, "Cullera i els Borja: el Cardenal Lluís de Milà i Borja, senyor de les rectories de Cullera i Sueca (1476-1508)", en III Jornades d'estudis de Cullera, Valencia, Benicull del Xúquer, 2000, pp. 383-384; ID., Els origens de la familia Borja, pp. 226-227.

86.- Vicent Terol I ReIG, "Fidels de Déu i fidels d'Al-là: cristians i sarraïns a la baronia-comtat d'Albaida (1435-1530)", en 750 Anys com a valencians: Albaida i la Vall 1245-1995, Ontinyent, Caixa d'Estalvis d'Ontinyent, 1995, pp. 117-118.

87.- Sobre este edificio cfr. Castillos de España, León, Everest, 1997, p. 1507; Joan Josep Soler NAVARro, Palau dels Milà i Aragò, Marquesos d'Albaida: recuperació i procés de restauració, Albaida, Ajuntament d'Albaida, 1999; y especialmente Abel Soler i Molina, Castells i Palaus de la Vall d'Albaida. Arquitectura i poder feudal, Ontinyent (Valencia), Ajuntament d'Ontinyent, 2001, pp. 87-92.

88.- Así lo indica el autor del Dietari del capellà en junio de 1477, al recordar la compra del señorío de Albaida "ha hon esta lo dit cardenal continuamente ab tota sa casa"; Josep SANCHIS SiverA (ed.), Dietari del capellà d'Anfós el Magnànim, Valencia, Acció Bibliografica Valenciana, 1932, p. 286. 
deshonrando su condición de eclesiástico el cardenal se juntó con una dama leridana llamada Àngela o Angelina Ram que le dio un número incierto de hijos: Jaume — primer conde de Albaida—, Lluís — canónigo de Segorbe y de Játiva-, y Caterina - futura condesa de Almenara por su casamiento con Gaspar de Pròixida — ${ }^{89}$; a los que, según otros autores, deben añadirse Perot $^{90}$, Francesc — sacristán (1494) y canónigo (1498) de Zaragoza- y Alfons, deán de Játiva ${ }^{91}$.

El palacio comenzó a edificarse aprovechando las torres y el muro que formaban parte de la antigua muralla. Tendría una planta en $L$, con patio adjunto, un acceso fortificado y la gran torre de Poniente, donde se conserva el escudo familiar de los Milà. Se trataba por tanto de una residencia nobiliaria que tendía a encerrarse sobre sí misma, íntima y poco comunicada, buscando probablemente el lujo y la suntuosidad de los interiores que el cardenal gustaba decorar, como en su residencia romana. De hecho, su gran fachada da al interior del patio de armas, destacando al exterior la sólida construcción de sus tres torres cuadradas, levantadas con materiales pobres de tapial y mazonería. El cardenal contaba además con otro palacio en Valencia, donde residía parte de la familia, el palacio episcopal de Aspa (Lérida) donde pasó algunas temporadas en los últimos años de su vida, y una casa noble en Carrícola asociada a la figura de Catalina Parra ${ }^{92}$.

El 27 de junio de 1472 se presentó en Valencia para recibir a su primo Rodrigo de Borja, recién nombrado por Sixto IV como cardenal legado ${ }^{93}$. Milà salió a recibirle en la puerta de San Vicente con los cuatro obispos de su casa. Probablemente ambos trataron entonces los proyectos dinástico-territoriales que acariciaban y se materializaron respectivamente en la creación del condado de Albaida por Juan II y el ducado de Gandía por Fernando el Católico. A diferencia de este último, el señorío de Albaida era un territorio más inestable, sometido a las violencias feudales sobre un campesinado que se afanaba por conservar la protección de la Corona y veían con recelo las pretensiones señoriales del cardenal. Meterse en aquel avispero estuvo a punto

89.- M. BAtllori, Obra completa, ad indicem; ID., La estirpe de los Borjas, p. 23.

90.- Vicent Terol i Reig, "Els origens de la familia Borja a la ciutat de Xàtiva," en Miquel Batllori (dir.), Diplomatari Borja. 1: Documents de l'Arxiu del Regne de València (1299-1429), Valencia, Edicions 3i4, 2002, pp. 226-227.

91.- Ventura Pascual i Beltrán, Játiva biográfica, Valencia, Renovación Tipográfica, 1931, pp. 285287; ID., "De algunos cardenales, canónigos y obispos setabenses", Anales del centro de cultura valenciana, 12 (1945), pp. 49-51.

92.- A. Soler i Molina, Castells i Palaus, pp. 102-103.

93.- J. SAnChis Sivera (ed.), Dietari del capellà, p. 370. 
de costarle la vida, pues en 1472 fue objeto de un atentado de "tres lançades" cuando regresaba a Albaida por el camino real cerca de Catarroja ${ }^{94}$.

Entre 1474 y 1478 Lluís Joan se hallaba de nuevo en Albaida resolviendo pequeños conflictos con el consell de Cullera — cuya rectoría ocupaba desde 1476 junto a la de Sueca- a causa de la reforma de la abadía que las autoridades urbanas pretendían sostener con las rentas del cardenal ${ }^{95}$. Éste también tenía quejas contra la Corona, pues en enero de 1475 encontramos su nombre entre los firmantes de las 560 reclamaciones presentadas a Juan II por los más diversos estamentos de Barcelona poco después de la invasión francesa del Rosellón ${ }^{96}$. Mientras tanto gobernaba desde la distancia su diócesis de Lérida, oponiéndose a que los franciscanos trasladaran su convento de San Lázaro a la parroquia de San Juan, y les animó a reedificar su casa en cualquier lugar de los extramuros de la ciudad ${ }^{97}$. Su vicario y colector pontificio desde 1472, Manuel de Montsuar, acudió varias veces a visitarle a Albaida para solucionar la candente cuestión de las constituciones de la catedral que Juan II se resistía a confirmar, y en especial para manifestarle los ardientes deseos de sus diocesanos de que regresara a su sede ${ }^{98}$. Sin embargo el cardenal se limitaba a efectuar pequeños desplazamientos, fijando su residencia en conventos dominicos donde mantenía cultivadas tertulias con la lectura de clásicos de la Antigüedad pagana y cristiana, como las epístolas de San Jerónimo o los textos de Virgilio que en 1476 leía su secretario a sus amistades barcelonesas ${ }^{99}$.

Sus preocupaciones señoriales se concentraron en el matrimonio de su hijo Jaime con Leonor de Aragón, nieta de Juan II, a quien el monarca otorgó el título de conde en 1477, y a quien el obispo donó la baronía y villa de Albaida (26.V.1478) prometiéndole una renta para su manutención de más de 30.000 sueldos anuales que quedó en papel mojado mientras los ingresos del cardenal alcanzaban los 168.000 sueldos anuales ${ }^{100}$. Aquel mismo año éste obtuvo además la encomienda del monasterio benedictino de San Vicente (Lérida) y el

94.- V. Pons Alòs, Cardenales y prelados, p. 61.

95.- V. Terol i ReIg, Cullera i els Borja, pp. 379-399.

96.- Santiago Sobrequés I VIDAL, La guerra civil catalana del segle XV: estudis sobre la crisi social i econòmica de la Baixa Edat Mitjana, vol. I: La societat catalana durant el conflicte, Barcelona, Ediciones 62, 1973, p. 340.

97.- J. L. VillanueVA, Viaje literario a las iglesias, vol. XVI, pp. 45 y ss.

98.- J. Lladonosa Pujol, Manuel de Montsuar, p. 268.

99.- María Dolores Cabré Montserrat, "El humanismo aragonés en tiempo del Rey Católico", Cuadernos de historia Jerónimo Zurita, 12/13 (1961), p. 44.

100.- Sobre el patrimonio de los Milà es preciso acudir a la documentación conservada en Archivo Histórico Nacional (sección Nobleza), Osuna, c. 4070, D. 2. Una semblanza del conde en Gonzalo Fernández de Oviedo, Batallas y quinquagenas, ed. J. Perez de Tudela Bueso, vol. 1, Madrid, 1983, pp. 361-364. 
de San Benigno (Dijon) en la diócesis de Langres (15.VI.1478), percibiendo unas rentas que al año siguiente le permitieron aumentar su patrimonio con la compra de Bélgida a los Bellvís.

Aunque es posible que Milà abandonara la península Ibérica en 1477-78 o en el verano de 1482, en la Curia se reprochaba su ausencia "buscando sus propias cosas y no las de Jesucristo, mirando al bien privado más que al público, olvidado de sus deberes sacerdotales"101. El curial Jacobo Gherardi da Volterra consideraba una traición el abandono de sus deberes ante la Sede Apostólica por una vida cómoda "entre sus amigos y parientes". Menos crítico resulta el comentario de su antiguo maestro Gaspare da Verona al comentar las razones del cambio de residencia por "maiore pace atque quiete suae domi fruens, pinguibus beneficiis gaudens, praesertim Ilerdensi episcopatu glorioso". Buscaba, en suma, la tranquilidad y los prestigiosos recursos que le permitieran vivir una vida sosegada ("vitam pacatissimam ducit") ${ }^{102}$.

No parece que a Fernando de Aragón le agradara la conducta del cardenal. Tras la caída de Otranto en manos de los turcos, le exhortó repetidas veces a dirigirse a Roma para ayudar al papa como pensaban hacer otros prelados castellanos y aragoneses (19 y 20.II.1481 ${ }^{103}$. Es posible que el papa también reclamara su presencia y — según Teodoro Llorente- el cardenal le envió desde Carrícola una larga epístola alegando su delicada salud y la necesidad de reposo, para terminar diciendo: "Bonum est nos hic, in Carricola nostra, cum Catalina Parra", tal vez una amante del cardenal ${ }^{104}$. Aunque se ha barajado su posible traslado a Roma en el verano de $1482^{105}$, no parece que Milà se moviera de su retiro levantino. Desde allí exigía al obispo de Vich —Guillem Ramón de Moncada - una pensión de 300 ducados que había logrado a través de sus contactos en la Curia y a pesar de las protestas de Fernando el Católico $(20 . I I I .1483)^{106}$. Su poder también se extendía al monasterio de Santa María de Roda donde obtuvo el priorato contra el candidato de la comunidad y la

101.- Jacopo GHerardi Da Volterra, Il diario romano di Jacopo Gherardi da Volterra, dal VII settembre MCCCCLXXIX al XII agosto 1484, ed. E. Carusi, Città di Castello, Editrice S. Lapi, 1904-1906, pp. 48 y 91 .

102.- Gaspare da Verona y Michele Canensi, Le vite di Paolo II, ed. G. Zippel, Città di Castello, Editrice S. Lapi,1904, p. 39.

103.- Antonio de la Torre y del Cerro, Documentos sobre las relaciones internacionales de los Reyes Católicos, vol. I, Barcelona, Consejo Superior de Investigaciones Científicas, 1949, pp. 130-133.

104.- T. LloRente, España en sus monumentos y artes, vol. II, pp, 777-778.

105.- P. Cherubini, Lettere concistoriali di Eugenio IV e Sisto IV, pp. 184 y 167.

106.- A. DE LA TORRE Y DEL CERro, Documentos sobre las relaciones internacionales, vol. II, pp. 32-33. 
voluntad del rey, quien no pudo impedir que Inocencio VIII diera la razón al cardenal uniendo el priorato a la mesa episcopal ilerdense (5.XI.1489) ${ }^{107}$.

El asunto de la pensión sobre el obispado de Vich dio lugar a un largo y tedioso enfrentamiento con Fernando de Aragón, que sumó a los reproches que éste hacía al cardenal por el incumplimiento de las promesas hechas a su hijo Jaime con motivo de su matrimonio con su sobrina Leonor de Aragón (12.VIII.1489 y 18.VII.1494) ${ }^{108}$. El conde de Albaida decidió cobrarse aquellas cantidades presentándose ante el cabildo leridano como procurador del obispo en 1491, en que data una carta de éste a los canónigos anunciando la llegada de su hijo ${ }^{109}$. Sin embargo el conde sólo logró exasperar al cabildo por las extorsiones y simonías cometidas, sin que sirvieran de nada los requerimientos y amenazas del rey (6.VI.1494) ${ }^{110}$. Tampoco parece que el auxiliar del obispo Vicente Trilles lograse calmar los ánimos, pues sólo conocemos sus querellas con el cabildo recogidas en las actas incompletas del sínodo convocado por el cardenal en Alfes (20.XI.1494). A estos pleitos se sumó el que mantuvieron sus vicarios con el gobierno municipal de Lérida (paheria) por la percepción de los diezmos en el verano de $1489^{111}$. Probablemente, arroje luz sobre este contencioso las contestaciones ofrecidas por el cardenal en junio de 1491 que se conservan en el archivo capitular ${ }^{112}$. Tras la visita de una delegación de los pahers a Albaida, Milà delegó toda la cuestión en su vicario, Manuel de Montsuar, a quien dotaba de tales poderes que sólo le quedaba la investidura episcopal ${ }^{113}$. Mientras tanto otro sobrino del cardenal, el noble Lluís del Milà i de Borja, promovía los descontentos de los estudiantes del Estudio General de Lérida en julio de 1492, exigiendo a las autoridades enviar emisarios a Barcelona para informar de los hechos ${ }^{114}$.

A pesar de estos episodios, Fernando el Católico continuó solicitando favores al cardenal, "amigo nuestro muy caro", como la concesión de la canonjía vacante por fallecimiento de Montsuar para el hijo del gobernador de Cataluña Requesens de Soler (17.XI.1491) ${ }^{115}$, o la cesión de la abadía de San Juan de las Abadesas, en el obispado de Vich que Milà tenía in comendam,

107.- Ibídem, vol. III, pp. 249-250.

108.- Ibídem, vol. III, pp. 252-255, 258-259, 277-278 y ss; vol. IV, p. 489.

109.- E. Flórez, España Sagrada, vol. XLVII, p. 86.

110.- Ibídem, vol. III, pp. 466-467.

111.- J. Lladonosa Pujol, Manuel de Montsuar, pp. 305-309.

112.- Arxiu Capitular de Lleida (Lérida), Instituciones civiles, Carpeta 1, Camisa 3, Cajón 136 (nº 6921 ).

113.- J. Lladonosa Pujol, Manuel de Montsuar, pp. 315-317.

114.- Josep Lladonosa Pujol, L'Estudi General de Lleida del 1430 al 1524, Barcelona, Institut d'Estudis Catalans, 1970, p. 55.

115.- A. DE la Torre y del CERro, Documentos sobre las relaciones internacionales, vol. III, p. 451. 
en favor de Vidal de Valgualnera, familiar de Alejandro VI y "persona muy acepta a nuestro seruicio" (30.III.1493) $)^{116}$.

En 1492 - sintiendo tal vez que su vida llegaba al ocaso — obtuvo licencia pontificia para disponer de sus bienes por testamento, y dos años después Fernando comenzó a urdir combinaciones a cuenta de los beneficios que quedarían vacantes si la enfermedad del cardenal se lo llevaba a la tumba. Sin embargo, aún le quedaban algunos años de vida al obispo de Lérida que no dejaba de exasperar al rey por el incumplimiento de sus promesas en la restauración de las iglesias, casas, fortalezas y castillos del obispado, cuya ruina conocía el Católico por los informes del cabildo. A la desidia del cardenal por enriquecer o reparar los edificios, se sumaban ahora las quejas de extorsión y escándalo contra ciertas personas allegadas. El monarca puso sobre aviso al lugarteniente general de Cataluña —el conde de Ribagorza — que al cerciorarse de la verdad de las acusaciones ordenó el secuestro de las rentas del obispo. Asustado, se limitó a entregar la mezquina cantidad de 6.000 sueldos para reparar la sacristía de la catedral ilerdense (22.XI.1498) incendiada en 1490 con graves pérdidas entre los ornamentos litúrgicos que allí se guardaban. Cuando se produjo la catástrofe una legación presidida por su vicario Montsuar se había desplazado al Albaida y a la corte instalada en Granada para solicitar la colaboración del cardenal y del rey ${ }^{117}$. De resultas de aquellas conversaciones el prelado promulgó un decreto impreso en 1498 concediendo indulgencias a los que contribuyesen a la reparación de la sacristía o a la construcción de la sillería del coro ${ }^{118}$. Con ello pretendía apoyar económicamente la restauración de la capilla y estimular la devoción de los fieles recordando las "quasi infinites relíquies" de la catedral. Tibias medidas para un prelado que se había convertido en el mayor acreedor censalista de Llombai cuando esta baronía fue comprada por Joan de Borja en 1494. Tres años más tarde añadió a su patrimonio la baronía de Otos gracias al millón y medio de sueldos que le reportó la venta de Planes; cifra equiparable a los préstamos que la ciudad de Valencia otorgó a Fernando el Católico entre 1484-94119.

Como se ha señalado, esta concentración de títulos era el resultado de una política de adquisiciones desplegada a lo largo de quince años, según una estrategia semejante a la de los Borja de Gandía tendente a la creación

116.- Ibídem, vol. IV, p. 161.

117.- J. Lladonosa Pujol, Manuel de Montsuar, pp. 301-304.

118.- E. Flórez, España Sagrada, vol. XLVII, pp. 86-87; Julia Benavent (ed.), Biblioteca dispersa: manuscrits i Incunables Valencians dels segles XIV al XVII, Valencia, Goaprint, 2007, p. 189; Seu Vella. L'Esplendor retrobada, Lérida, Generalitat de Catalunya. Departament de Cultura, Fundació "La Caixa", 2003, pp. 354-356.

119.- V. Terol i Reig, Els origens de la familia Borja, pp. 226-227. 
de un mini-estado en las comarcas valencianas de las montañas. El gobierno de estas tierras no fue, sin embargo, asunto fácil pues en 1498 el conde de Albaida se enzarzó en un áspero conflicto con Francesc Aguiló de Romeu, señor de Petrer, Albalat y otros señoríos, con episodios de violencia y enojosos recursos a la autoridad que acabaron resolviéndose en favor del conde. Mientras tanto, el colchón económico era garantizado por las saneadas rentas del cardenal caracterizadas — según Terol i Reig — por su diversificación, internacionalización y origen eminentemente eclesiástico pues procedían de los beneficios acumulados, cuyo capital era reinvertido en el mercado valenciano de los censales ${ }^{120}$. Esta entente económico-familiar no impidió que se suscitaran conflictos entre el cardenal y su hijo por el gobierno y las rentes del valle de Albaida. En 1502 el primero denunció las arbitrariedades de su heredero al usurpar las rentas de la villa cometiendo violencias contra sus habitantes y atentando contra sus propios derechos como "senyor, detenidor e possehidor de la dita vila e condat de Albaya"121. Por esta razón el cardenal inició acciones legales ante la Real Audiencia de Valencia, logrando que el virrey le restituyese las funciones fiscales que se había apropiado el conde.

\section{ACTIVIDAD PASTORAL y AVATARES FAMILIARES}

De su actividad episcopal en Lérida, casi siempre delegada, contamos con unas breves notas relativas a la visita pastoral ordenada en 1497 y al sínodo celebrado por su procurador Martín Juan de Alcoleia en abril de $1500^{122}$. Manuel de Montsuar fue su vicario y administrador desde que Milà le reintegrara en el oficio hasta su fallecimiento en $1491^{123}$. Fue sustituido por Vicente Trilles, que consagró el santuario de la Mare de Déu de Butsènit (1495) y confirió la tonsura al leridano Miguel Cavala. En el ámbito litúrgico, el obispo confirmó en 1484 el orden en las procesiones de las rogaciones y dictó ciertas prescripciones recogidas en el misal y el ritual de la diócesis que mandó imprimir en fecha y lugar desconocido ${ }^{124}$. Bajo su mandato se editó el primer breviario impreso en Cataluña: el Breviarium Ilerdense publicado el 16 de agosto de 1479 por el impresor alemán Enric Botel, y del que se conserva un magnífico ejemplar impreso sobre vitela y decorado a mano ${ }^{125}$.

120.- V. Terol i Reig, Cullera i els Borja, pp. 385-386.

121.- V. Terol i Reig, Fidels de Déu i fidels d'Al·là, pp. 122-123.

122.- J. L. Villanueva, Viaje literario a las iglesias, vol. XVI, pp. 44-46.

123.- J. Lladonosa Pujol, Manuel de Montsuar, pp. 55-56.

124.- Ibídem, pp. 43-48.

125.- Missale Vicense, 1496, ed facisimilar reducida a cargo de Francesc Xavier Altés i Aguiló, Barcelona, Institut d'Estudis Catalans, 2001. 
Años después, el mismo Botel acometió entre 1495 y 1498 la edición del misal del obispado, y en esta última fecha imprimió en catalán el decreto de indulgencias anteriormente citado que constituye un raro testimonio de los inicios de la imprenta en Lérida ${ }^{126}$. M. Jiménez Catalán también se hace eco de un Missale mixtum carente de indicaciones tipográficas que "fue impreso en Lérida en la época del obispo D. Luis del Milà" 127.

Durante su mandato se unieron las cofradías de San Salvador y de Santa María la Antigua, recibiendo nuevas ordenaciones y privilegios gestionados por Manuel de Montsuar en $1482^{128}$. También debió prestar su apoyo al antiguo hospital de Santa María de Lérida pues sus armas — representadas en un bello escudo ojival en bajorrelieve- adornan la galería septentrional del patio ${ }^{129}$. El cardenal tampoco perdió su gusto por los objetos suntuarios o la actividad de la escolanía de la catedral. El 8 de noviembre de 1503 recibió del cabildo valenciano una colección de ornamentos sagrados que incluía una capa de damasco blanco "ab fresaüra e capiró brodats d'or e de seda, ab ymatges brodades d'or e de seda, e dos troços de fresaüra ab dos ymages brodades d'or e de seda"; una casulla de damasco con encajes de oro y seda, un cortinaje de ceutí carmesí ("en lo qual ha dos cortines e cel e un crobrellit e dos tovalloles"; y un "sinal de damàs blanch, ab les flors de seda verda e de grana" 130 . Ornamentos que podrían estar relacionados con el lujoso terno (casulla y capa pluvial) de Calixto III conservado en el museo diocesano de Lérida y realizado en Roma hacia 1455-1458, que pudo haber donado Milà ${ }^{131}$. También se ha atribuido al cardenal el encargo o donación de la Vera Cruz

126.- Julián ACEBRón Ruiz, "Sobre la versión catalana del Fiore di virtú, su autor y sus avatares", en Fermín Sierra Martínez (ed.), Literatura y transgresión. Homenaje al profesor Manuel Ferrer Chivite, Amsterdam-Nueva York, Rodopi, 2004, pp. 45-46.

127.- Manuel Jiménez Catalán, Apuntes para una bibliografía ilerdense de los siglos XV al XVIII, Barcelona, Tipografía "L'Avenç", 1912, pp. 71-75.

128.- Francisco Esteve Perendreu, "Los hábitos de coro del cabildo de Lléida y su impugnación”, en Guillermo Redondo Veintemillas, Alberto Montaner Frutos y María Cruz García López (eds.), Actas del I Congreso Internacional de Emblemática General, Zaragoza, Institución Fernando el Católico, 2004, pp. 676-677.

129.- Antoni ConeJo I DA Pena, Assistència i hospitalitat a l'edat mitjana. L'arquitectura dels hospitals catalans: del gòtic al primer renaixement (tesis doctoral), vol. I, Barcelona, Universitat de Barcelona, 2002, p. 531 y láms. 184 y 188.

130.- Archivo de la Catedral de Valencia, Leg. 3688, prot. de Jaume Esteve, cuaderno 2 (véanse las carpetas del genealogista Lluís Cerveró en el Archivo del Reino de Valencia).

131.- La casulla lleva las armas pontificias bordadas en la parte superior, con San Juan Bautista y San Antonio en la parte baja, mientras en la parte de atrás se representa a la Virgen con el Niño, San Juan Evangelista y Santo Tomás (?). La capa pluvial lleva grabada en su parte trasera una escena de la Sagrada Familia con la Vírgen, San José y San Juan Bautista contemplando al Niño Jesús dormido sobre un lecho; cfr. Rosa M. Martin i Ros y Ximo Company i Climent, "Tern del papa Calixt III (Casulla i Capa Pluvial)", en La Seu Vella de Lleida, La catedral, els promotors, els artistes, s. XIII a s.XV, Generalitat de Catalunya-Departament de cultura, Barcelona, 1991, pp. 120-123. 
conservada en la iglesia arciprestal de Albaida: un excepcional relicario de $63,7 \mathrm{~cm}$ de alzada que debió contener alguna reliquia o la sagrada forma en la procesión del Corpus Christi ${ }^{132}$; devociones ambas que Lluís Joan promovió en Bolonia, Viterbo, y probablemente en Lérida a juzgar por el decreto de indulgencias de 1498 .

Durante su mandato se emprendió la restauración de la capilla de la catedral y la restructuración del nuevo coro imitando el modelo de Zaragoza y Tarragona realizados por el taller de Franci Gomar. El contrato fue firmado en 1497 por el capítulo catedralicio y los maestros de obra Joan Just y Antonio Virto, o Bierto, que tenía taller en Zaragoza y realizaron la obra entre 1500 y $1502^{133}$. Se renovó la doble sillería, se instaló una nueva tribuna para el predicador y se encargó un nuevo órgano al tallista barcelonés Climent Carbonell para reemplazar el que se destruyó en el incendio de $1483^{134}$. Aunque es difícil precisar la responsabilidad del prelado, no sería difícil advertir su interés por este embellecimiento de la catedral, y el auge de las representaciones sagradas durante su gobierno. Nos referimos a la celebración del Corpus Christi y del misterio de la muerte y Asunción de la Virgen recuperada en 1497 con la procesión del enterramiento de la Madre de Dios y el drama representando el ascenso de su alma al cielo. Aunque se ha conjeturado la influencia de Valencia o del misterio de Elche ${ }^{135}$, la reactivación del misterio ilerdense podría estar relacionada con los gustos del que fuera uno de los principales organizadores de la fastuosa celebración de Viterbo de 1462.

El obispo de Lérida también mantuvo relación con el Estudio General de Lérida donde estudiaron algunos de sus sobrinos: el valenciano Francì del Milà, datado en 1497; su hermano Lluìs del Milà, que en 1491 cursaba en la Facultad de Letras cuando defendió ante sus autoridades el fuero eclesiástico de algunos estudiantes, pues él mismo era beneficiado de la capilla de San Valerio en la sede ilerdense ${ }^{136}$; o Pere del Milà, que estudiaba leyes en 1490 y el 30 de octubre fue designado por su tío para el oficio de vicario general de la diócesis ${ }^{137}$.

132.- Josep Ferre i Puerto, "L'art medieval a la Vall d'Albaida: la Vera Creu d'Albaida i el seu context", en 750 Anys com a valencians, pp. 197-199.

133.- Francesc Fité i Llevot, "Liturgia i cultura a la Seu Vella de Lleida”, en Seu Vella. L'Esplendor retrobada, pp. 100-103.

134.- Ibídem, pp. 103-104.

135.- Gabriel Alonso Garcia, Los maestros de la «Seu Vella de Lleida» y sus colaboradores, Lérida, Instituto de Estudios Ilerdenses, 1976, pp. 192-223; F. Fité I Llevot, Liturgia i cultura, pp. 108-109.

136.- J. Lladonosa Pujol, Manuel de Montsuar, p. 320.

137.- J. Lladonosa Pujol, L'Estudi General de Lleida, p. 105. 
Mientras tanto en Roma se consideraba a Milà un cardenal ausente "que se encuentra en España desde hace treinta años" (28.IX.1500) ${ }^{138}$. Alejandro VI le apoyaba desde la distancia concediéndole la dispensa de estar ausente de Roma sin prejuicio de sus derechos cardenalicios (30.VII.1496), y otorgó diversos beneficios a sus familiares, especialmente sus hijos Francesc y Alfons, que en 1494 fueron nombrados respectivamente sacristán de Zaragoza y canónigo y deán de la colegiata de Játiva ${ }^{139}$; sin olvidar a su sobrino Francesc del Milà en su solicitud de una canonjía en la catedral de Barcelona en 1474, o el propio conde de Albaida, a quien el papa facilitó el ingreso en la orden militar de Santiago de la Espada (30.VII.1496) ${ }^{140}$.

Entre los familiares del cardenal que permanecían en Italia habría que contar a su sobrina Adriana del Milà —encargada de algunas damas borgianas del Vaticano- y su nieta Juana del Milà d'Aragó — hija del conde de Albaida - que casó en 1506 con Jofré de Borja, hijo legitimado de Alejandro $\mathrm{VI}^{141}$. En el séquito que acompañó a Lucrecia Borja a Ferrara en 1502 también figuraba un Jofré del Milà "nepote del papa"142. Finalmente cabe recordar a Joan del Milà, hijo de Pere del Milà y sobrino del cardenal, a quien el papa se empeñó en casar con su sobrina Isabel Lucrecia de Borja Lançol. Tras una inicial orientación eclesiástica como abad comendatario de San Salvatore en Chiusi (24.VII.1462) ${ }^{143}$, Pere había servido a Juan II en la guerra civil y acabó desplazándose a Roma donde murió en $1498^{144}$. La relación con su esposa Isabel Lucrecia no fue fácil, a tenor de las quejas que ésta hacia llegar a su tío por las vejaciones a las que se veía sometida por no recibir los 6.000 sólidos prometidos en el contrato matrimonial para el sostenimiento de su casa (13.III.1494) ${ }^{145}$. Sea como fuere, el matrimonio manifiesta el interés de Alejandro VI por no perder los lazos con sus primos valencianos.

138.- Eugenio AlbéRI (ed.), Relazioni degli ambasciatori veneti al Senato, serie II, vol. III, Florencia, Società Editrice Fiorentina, 1846, pp. 5-6; Marino SANudo, Diarii, ed. R. Fulin, vols. I-XIV, Venecia, 1879-1903, ad indices.

139.- Tras el fallecimiento de Alfons en 1504 el deanato volvió a su padre; V. Pons Alòs, Cardenales y prelados, p. 61.

140.- Maria Toldrà, y Teresa Huguet-Termes, "La butlla de la legació de Roderic de Borja ad regna Hispaniarum, copiada per Joan Feixes, servidor de Calixt III (BC, ms. 482)", Revista Borja. Revista de l'Institut Internacional d'Estudis Borgians, 3 (2011), p. 103.

141.- Ferdinand Gregorovius, Lucrecia Borja a partir de documents i epistolaris del seu temps, ed. de M. Toldrà, Valencia, Tres i Quatre, 2008, pp. 61-62.

142.- Zамвотті, Diario Ferrarese, vol. II, p. 336.

143.- Annibale Ilari, “Appendice: i familiari di Alessandro VI”, en M. Chiabò, S. Maddalo y M. Miglio (coords.), Roma di fronte, vol. I, pp. 305 y 313-316.

144.- Rafael Martí de Viciana, Segunda parte de la crónica de Valencia, Valencia, Sociedad Valenciana de Bibliófilos, 1881, pp. 174-176.

145.- Miquel Batllori (ed.), De València a Roma. Cartes triades dels Borja, Barcelona, Quaderns Crema, 1998, pp. 92-93. 
Durante sus últimos años de vida, el cardenal del Milà mejoró sus relaciones con Fernando el Católico. El 16 de diciembre de 1500 escribió al monarca lamentándose de un insulto que había recibido en su villa de Albaida. El rey prometió castigarlo si se repetía y más adelante le agradeció que hubiera retirado la excomunión lanzada en la querella por la pensión del obispado de Vich, pidiéndole que hiciera lo mismo en el asunto de la abadía de San Victorián ${ }^{146}$. Aquel año Lluís Joan pagó 800 ducados por el impuesto de la décima contra el turco y 1.000 sueldos por los gastos de la guerra de Pallars como súbdito del rey ${ }^{147}$. Otra cuestión era la de sus beneficios, cuyas rentas intentaba traspasar al conde de Albaida por vía de concordia o coadjutoría contra el parecer del rey, que en 1502 escribió al embajador en Roma mostrando su oposición a aquellos enjuagues y su perplejidad ante la reclamación del cardenal sobre la abadía de San Victorián en virtud de una bula de Paulo II (20.X.1503) $)^{148}$.

El prelado no mostraba demasiados escrúpulos hacia las actividades delictivas de su clero, que se arrimaba a su protección para escapar de la justicia. El 27 de noviembre de 1507 el alcalde Soler comunicaba al cardenal "ço que lo Reverendíssim Senyor Cardenal demane a tots capellans e coronats un gran dret que té sobre aquells que serie cosa de grandíssim dany a la Ciutat e als poblats de aquella si no s'i fa cara"149. Dos años después, en abril de 1509, el fiscal del obispo liberaría a dos tonsurados delincuentes que habían sido detenidos por la autoridad civil.

Poco sabemos de los últimos años de nuestro biografiado. En abril de 1507 el rey solicitó al papa el nombramiento de Joan de Requesens como coadjutor del cardenal de Albaida "que agora está muy enfermo y en la hedad decrepita a causa de lo qual haunque quiera no puede regir el dicho obispado"150. Este había dado al rey su conformidad, accediendo a la designación de Requesens como su sucesor en la sede, a cambio de entregar a un hermano del conde de Albaida 10.000 sueldos de pensión sobre las rentas de la diócesis. Mientras

146.- J. Goñ I Gaztambide, Mila, Luis Juan de, vol. Suplemento, p. 492.

147.- El pago por la décima contra el turco se repitió en 1501, 1502 y 1503; cfr. P. DE Roo, Material para una historia, vol. I, pp. 74-79 y 81-84; PASCUAL I Beltrán, Játiva biográfica, p. 287. El maestro de ceremonias pontificio registra 8.800 ducados pagados por el cardenal en junio de 1500; Jacob BurcKARDT, Liber notarum ab anno 1483 usque ad annum 1506, ed. E. Celani, vol. II, Città di Castello, Editrice S. Lapi, 1907-1942, p. 227.

148.- J. GoÑ Gaztambide, Mila, Luis Juan de, vol. Suplemento, p. 492.

149.- J. Lladonosa Pujol, L'Estudi General de Lleida, p. 83.

150.- Joaquín Manglano y Cucalo de Montull, (Barón de Terrateig), Política en Italia del Rey Católico (1507-1516). Correspondencia inédita con el embajador Vich, vol. II, Madrid, Consejo Superior de Investigaciones Científicas, 1963, pp. 33-34. 
tanto el rey Católico podía contar con el voto del cardenal en un hipotético cónclave en julio de $1507^{151}$.

La fecha de su fallecimiento ha sido objeto de múltiples conjeturas, probablemente por la larga enfermedad que mermó sus capacidades. Los datos que aportamos desmienten la fecha de 1504 que Pascual i Beltrán ${ }^{152}$, y Villagrasa y Teruel ${ }^{153}$ proponían para su deceso. Otro grupo de autores lo datan a fines de 1507: Escolano y Chacón el 10 de septiembre de $1507^{154}$, Goñi Gaztambide el 22 de septiembre ${ }^{155}$, y Vieira en 10 de diciembre del mismo año ${ }^{156}$. En realidad, en noviembre de 1507 el maestro de ceremonias Paris de Grassis aún lo da por vivo y el 22 de diciembre de 1508 no lo menciona entre los cardenales difuntos ${ }^{157}$. Con razón Villanueva lo sitúa en el palacio leridano de Aspa en marzo de $1508^{158}$. Los conflictos con las autoridades leridanas obligan a retrasar su fallecimiento hasta noviembre de 1509 por lo menos, en que el cardenal escribía al bayle quejándose de los problemas de recaudación que encontraba en el Valle de Arán (5.XI.1509) ${ }^{159}$. De ahí que podamos dar por buena la fecha del 9 de diciembre de 1510 que Eubel y Batllori aportan para su fallecimiento ${ }^{160}$. Una tradición señala que al sentirse enfermo quiso trasladarse al valle de Albaida y en el camino se halló tan desfallecido que el barón de Bélgida le llevó a su palacio, donde expiró ${ }^{161}$. Sus restos se enterraron en la "capilla de Alcoleya", hasta que en 1511 fueron trasladados a la catedral de Lérida. Finalmente en 1574 llevaron su cuerpo a la iglesia del convento dominico de Santa Ana fundado por el cardenal en la villa de Albaida, tal vez para que sirviera de panteón familiar.

151.- José María Doussinague, "Fernando V el Católico en las vistas de Savona de 1507”, Boletín de la Real Academia de la Historia, 108 (1936), p. 116.

152.- Ventura Pascual i Beltrán, De algunos cardenales, canónigos y obispos setabenses, p. 51.

153.- F. de Villagrasa y Teruel, Antigüedad de la Iglesia Catedral de Segorbe, pp. 158-161.

154.- Chacón, Vitae et res gestae Pontificum, vol. II, cols. 989-990.

155.- J. GoÑ Gaztambide, Mila, Luis Juan de, vol. Suplemento, p. 492.

156.- Nuno Miguel Carvalho VIeIRa, Obispos de Segorbe: retratos, Castellón, El Autor, 2008, pp. 68-69.

157.- Lorenzo CARdella, Memorie storiche de' cardinali della santa Romana Chiesa, vol. III, Roma, Stamperia Pagliarini, 1793, p. 272.

158.- J. L. VillanUEVA, Viaje literario a las iglesias, vol. XVI, p. 48.

159.- Archivo de la Corona de Aragón (Barcelona), Generalitat, Correspondencia, n. 929.

160.- Conrad Eubel, Hierarchia Catholica Medii Aevi, vol. II, Patavii, Il Messaggero di S. Antonio, 1898-1923, pp. 12, 34-36; M. BATLloRI, La estirpe de los Borjas, p. 23.

161.- T. Llorente, España en sus monumentos y artes, vol. II, p. 778 


\section{Conclusiones}

El juicio de los historiadores no han sido benévolo con el personaje al que se dedican estas páginas: sus contemporáneos reprocharon al cardenal su indolencia y desidia en ejercicio de sus cargos eclesiásticos a los cuales había accedido más por vínculos familiares que por cualidades personales. Woodward le considera una persona de una capacidad mediocre que no dejó ninguna impronta en la historia de la Iglesia, desapareciendo pronto de la escena política italiana ${ }^{162}$. En realidad, Lluís Joan formaba parte de una generación de eclesiásticos que, como Rodrigo Borja, trató de conciliar sus intereses familiares y sus responsabilidades eclesiásticas con un indudable desequilibrio en favor de las primeras. Sin duda no estuvo a la altura del proyecto que su poderoso tío dispuso para él, y su figura quedó eclipsada por la de su primo, con quien compartió sus carencias morales sin contar con su salud física ni sus cualidades políticas.

Sin embargo, Milà mostró una capacidad de integración en el ambiente curial romano, estrechando relaciones con personajes de la talla del cardenal Ammannati, el humanista Gaspare da Verona o el poeta Antonio Geraldini, y se ganó la confianza del propio Pío II. Todo ello revela que estamos ante un hombre de cierta talla intelectual y una sensibilidad artística desarrollada en sus empresas italianas e hispanas. Su acción pacificadora en Bolonia y en Lérida refleja su temperamento conciliador, y su proyecto señorial en el condado de Albaida su voluntad de colaborar con el poder real, aunque no faltaran desencuentros por cuestiones fiscales o jurisdiccionales. Con razón su contemporáneo Gonzalo Fernández de Oviedo le describe como un "valeroso príncipe de la Iglesia de Dios" preocupado por el patrimonio familiar pues "fue fama que le dejó [a su hijo el conde de Albaida] un gran tesoro"163.

Estas capacidades no acabaron de encajar con su perfil de un hombre de Iglesia. Los juicios en este sentido han sido implacables entre los historiadores. Goñi Gaztambide afirma que "su acción como obispo fue funesta y como cardenal, nula"164, limitándose a esquilmar sus diócesis — como señala Pons Alòs- "en beneficio del crecimiento de su patrimonio familiar"165. De ahí que pueda considerarse al cardenal un fruto estéril del nepotismo de Calixto III, paradigma de cardenal secularizado que asfixió con sus intereses familiares sus responsabilidades eclesiales. Su absentismo, su amancebamiento, y

162.- William Harrison Woodward, Cèsar Borja, prólogo de J. Benavent y revisión de M. Toldrà, Valencia, Tres i Quatre, 2005, p. 46.

163.- G. FERnÁNDEZ DE Oviedo, Batallas y quinquagenas, pp. 361 y ss.

164.- J. GoÑ Gaztambide, Mila, Luis Juan de, vol. Suplemento, p. 492.

165.- V. Pons Alòs, Cardenales y prelados, p. 59. 
VIDA Y EMPRESAS DEL CARDENAL LLUÍS JOAN DEL MILÀ: PROMOCIÓN ECLESIÁSTICA

el uso de sus rentas en beneficios particulares constituyen lacras difícilmente justificables. Todo ello no impide que el cardenal tuviera algunas iniciativas litúrgicas y editoriales que proporcionan algunos destellos en su labor pastoral donde su autoridad no dejó de hacerse presente. Quizá sea éste el campo donde mejor se aprecien las sinergias religiosas y culturales entre la península Ibérica y la Italiana que el cardenal de Albaida, con sus luces y sus sombras, fue capaz de unificar y promover. 
